\title{
Screening tests for endometrial cancer in the general population
}

\section{DOI:}

10.1002/14651858.CD013859

\section{Document Version}

Final published version

Link to publication record in Manchester Research Explorer

\section{Citation for published version (APA):}

Njoku, K., O'flynn, H., Jones, E., Ramchander, N. C., White, H., Macey, R., \& Crosbie, E. J. (2021). Screening tests for endometrial cancer in the general population. Cochrane Database of Systematic Reviews.

https://doi.org/10.1002/14651858.CD013859

\section{Published in:}

Cochrane Database of Systematic Reviews

\section{Citing this paper}

Please note that where the full-text provided on Manchester Research Explorer is the Author Accepted Manuscript or Proof version this may differ from the final Published version. If citing, it is advised that you check and use the publisher's definitive version.

\section{General rights}

Copyright and moral rights for the publications made accessible in the Research Explorer are retained by the authors and/or other copyright owners and it is a condition of accessing publications that users recognise and abide by the legal requirements associated with these rights.

\section{Takedown policy}

If you believe that this document breaches copyright please refer to the University of Manchester's Takedown Procedures [http://man.ac.uk/04Y6Bo] or contact uml.scholarlycommunications@manchester.ac.uk providing relevant details, so we can investigate your claim.

\section{OPEN ACCESS}


Cochrane Database of Systematic Reviews

\section{Screening tests for endometrial cancer in the general population (Protocol)}

Njoku K, O'Flynn H, Jones E, Ramchander NC, White H, Macey R, Crosbie EJ

Njoku K, O'Flynn H, Jones E, Ramchander NC, White H, Macey R, Crosbie EJ. Screening tests for endometrial cancer in the general population (Protocol). Cochrane Database of Systematic Reviews 2021, Issue 1. Art. No.: CD013859. DOI: 10.1002/14651858.CD013859. 
TABLE OF CONTENTS

HEADER 1

ABSTRACT

BACKGROUND

Figure 1.

OBJECTIVES

METHODS

ACKNOWLEDGEMENTS

REFERENCES

ADDITIONAL TABLES

APPENDICES

HISTORY

CONTRIBUTIONS OF AUTHORS

DECLARATIONS OF INTEREST 
[Diagnostic Test Accuracy Protocol]

\section{Screening tests for endometrial cancer in the general population}

Kelechi Njoku ${ }^{1}$, Helena O'Flynn¹, Eleanor Jones ${ }^{1}$, Neal C Ramchander ${ }^{1}$, Helen White², Richard Macey ${ }^{3}$, Emma J Crosbie ${ }^{1,4}$

1Division of Cancer Sciences, Faculty of Biology, Medicine and Health, The University of Manchester, Manchester, UK. 2Division of Population Health, Health Services Research \& Primary Care, School of Health Sciences, Faculty of Biology, Medicine and Health, The University of Manchester, Manchester, UK. ${ }^{3}$ Nuffield Department of Orthopaedics, Rheumatology and Musculoskeletal Sciences (NDORMS), University of Oxford, Oxford, UK. 4Manchester Academic Health Science Centre, Manchester University NHS Foundation Trust, Manchester, UK

Contact address: Emma J Crosbie, emma.crosbie@manchester.ac.uk.

Editorial group: Cochrane Gynaecological, Neuro-oncology and Orphan Cancer Group.

Publication status and date: New, published in Issue 1, 2021.

Citation: Njoku K, O'Flynn H, Jones E, Ramchander NC, White H, Macey R, Crosbie EJ. Screening tests for endometrial cancer in the general population (Protocol). Cochrane Database of Systematic Reviews 2021, Issue 1. Art. No.: CD013859. DOI: 10.1002/14651858.CD013859.

Copyright @ 2021 The Cochrane Collaboration. Published by John Wiley \& Sons, Ltd.

\section{A B S T R A C T}

\section{Objectives}

This is a protocol for a Cochrane Review (diagnostic). The objectives are as follows:

To assess the diagnostic accuracy of potential screening tests for the detection of atypical hyperplasia (pre-cancer) and endometrial cancer of all stages and grades in asymptomatic (healthy) women in the general population.

\section{Secondary objectives}

- To determine the optimal endometrial thickness cut-off value using transvaginal ultrasound scan for the screening of asymptomatic women for endometrial cancer and atypical hyperplasia.

- To investigate sources of heterogeneity in endometrial cancer screening studies, including:

* characteristics of the studied population including age, menopausal status (pre- and postmenopausal), country of study and risk status (body mass index (BMI) categories, diabetes mellitus, polycystic ovary syndrome (PCOS));

* characteristics of index test such as cytological classification used and sampling device;

* methodological quality (low risk of bias compared to high risk of bias);

* disease factors (endometrioid versus non-endometrioid, low grade versus high grade). 


\section{B A C K G R O U N D}

\section{Target condition being diagnosed}

Endometrial cancer, also known as uterine or womb cancer, is a type of cancer that originates in the inner lining of the womb (the endometrium) and is mostly a disease of postmenopausal women. Globally, there were an estimated 380,000 incident cases in 2018 and about 89,000 died from their disease, making endometrial cancer the sixth most common female cancer, and the 14th leading cause of death from cancer in women (Bray 2018; Lortet-Tieulent 2018). Its incidence is projected to rise in the coming years in parallel with the growing prevalence of obesity (Crosbie 2014). Declining rates of hysterectomy for benign womb conditions and an ageing population also contribute to the rising trends (Morice 2016; Temkin 2016).

Approximately two-thirds of women with endometrial cancer reside in the developed world, especially in countries with a high human development index (Lortet-Tieulent 2018). Most endometrial cancers are sporadic, with only about $5 \%$ occurring in the context of an inherited predisposing condition, such as Lynch syndrome (Ryan 2019; Sundar 2017). Diabetes mellitus, hypertension, polycystic ovary syndrome, use of tamoxifen and oestrogen-only hormone replacement therapy are other important risk factors (Njoku 2019).

There are various histological subtypes of endometrial cancer that differ in incidence, clinical presentations, prognoses and associated risk factors. These include endometrioid endometrial cancer, serous endometrial cancer, clear cell endometrial cancer and uterine carcinosarcoma (Colombo 2016). Whilst the majority of the endometrioid cancers are low grade, and in general have a good prognosis, a significant minority are high grade (aggressive-looking and faster-growing) and are associated with poorer outcomes (Brinton 2013). The non-endometrioid cancers, on the other hand, are mostly high grade and are often diagnosed at an advanced stage (Brooks 2019; Suarez 2017). There is emerging evidence to suggest that the growing incidence of endometrial cancer in several Western countries is due to an upward trend in the diagnosis of the clinically aggressive, non-endometrioid endometrial cancers (Clarke 2019; Faber 2017; Urick 2019). Screening tests that are able to detect all endometrial cancers at an early stage, especially the non-endometrioid tumours, are likely to improve survival outcomes.
The processes underlying endometrial cancer development are dependent on the histological subtype (Figure 1; Brinton 2013). Endometrioid tumours, for instance, result from the unopposed stimulation of the epithelial lining of the womb by the female sex hormone, oestrogen, which results in hyperplasia without atypia (i.e. individual cells still look relatively normal, although there is an overgrowth of cells), with the potential to evolve into atypical hyperplasia (where individual cells look more abnormal), an endometrial cancer precursor lesion, and ultimately endometrial cancer (Setiawan 2013). There is substantial histopathological overlap between severe atypical hyperplasia and low-grade endometrial cancer, making a diagnostic distinction between the two difficult and unnecessary in the context of screening. A particular gene fault, phosphatase and tensin homologue (PTEN) mutation, is the most frequent genetic abnormality in endometrioid endometrial cancer and occurs early in its development (Figure 1; Cancer Genome Atlas Research Network 2013; Levine 1998. It may thus be a potential target for endometrial cancer screening, although studies have shown that it is insufficient on its own to initiate tumour formation (Mutter 2000). Nonendometrioid endometrial cancers, on the other hand, are oestrogen-independent. Serous endometrial cancer, for instance, commonly develops on the surface of an endometrial polyp on a background of an atrophic endometrium (El-Sahwi 2012; Lax 2000). Although serous tumours are frequently diagnosed at an advanced stage, p53 gene faults have been suggested to occur early in serous tumour development (Figure 1). This raises the possibility that p53 gene faults may be targets for early detection of serous tumours (Sherman 1995). Uterine carcinosarcomas and clear cell endometrial cancers are other aggressive non-endometrioid types of endometrial cancer (Cherniack 2017; Le 2017). Whilst the underlying gene faults of carcinosarcoma closely resemble those of serous endometrial tumours, clear cell tumours share similar genetic abnormalities with endometrioid endometrial cancer (Cherniack 2017; Le 2017; Urick 2019). Recently, a classification by the Cancer Genome Atlas (TCGA) Research Network categorised endometrial cancer into four groups based on specific gene faults: polymerase epsilon (POLE) ultramutated, microsatellite instability (MSI) hypermutated, copy number low tumours and copy number high tumours (Cancer Genome Atlas Research Network 2013). This classification has been shown to predict outcomes for women with endometrial cancer (Stelloo 2015; Talhouk 2017). 
Figure 1. Endometrial cancer development pathways and associated gene faults

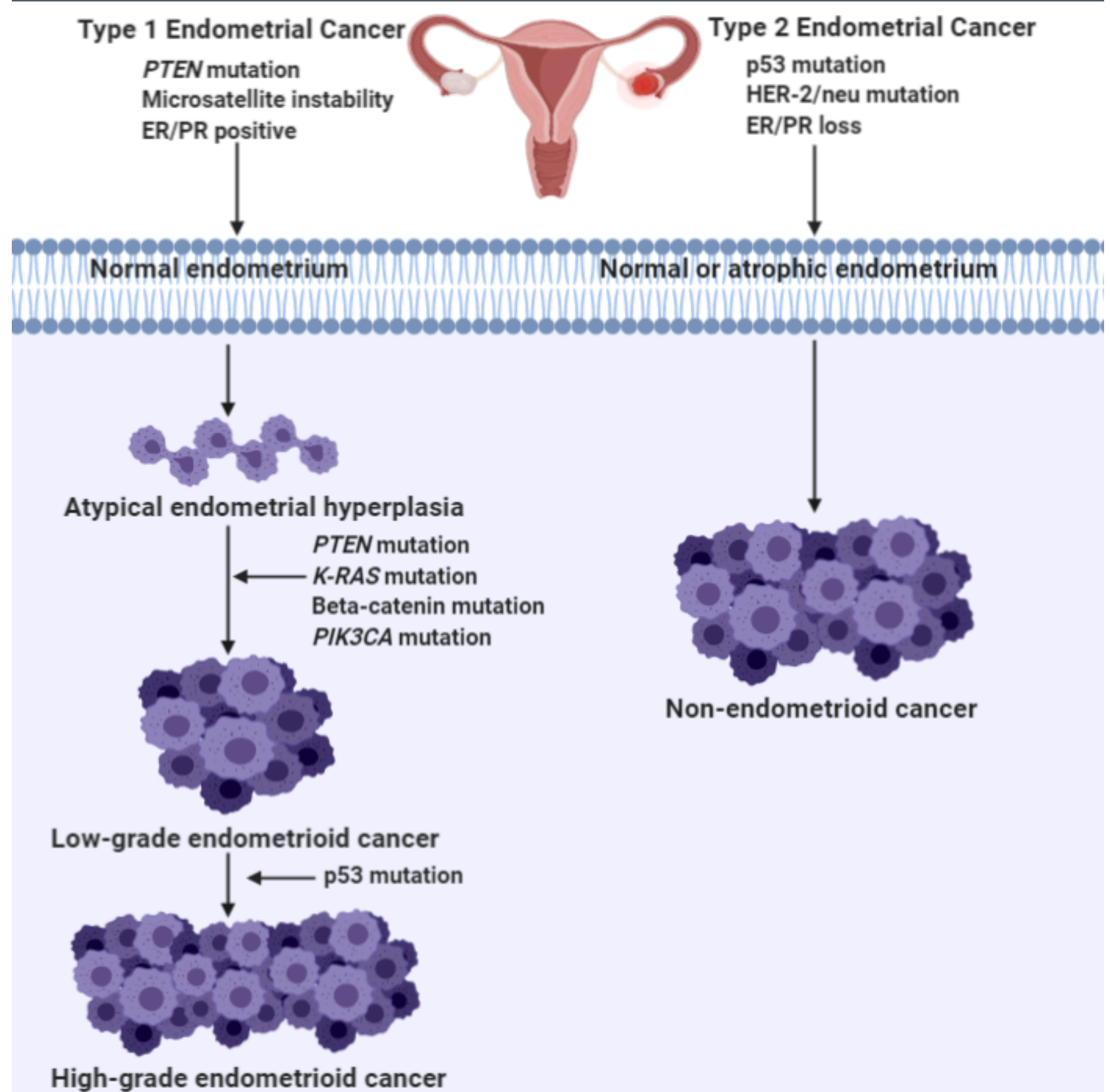

Postmenopausal bleeding (PMB) is the most frequent symptom of endometrial cancer. It is, however, a non-specific marker of the disease. Although $90 \%$ of women with endometrial cancer initially present with PMB, only $5 \%$ to $10 \%$ of women with PMB are diagnosed with endometrial cancer (Clarke 2018; Gredmark 1995). Irregular or heavy pre- or perimenopausal bleeding, haematuria, abnormal vaginal discharge, abdominal distension, pelvic pain and weight loss are other important but less common symptoms (Braun 2016). It is not unusual for asymptomatic women to be diagnosed with endometrial cancer. As an example, endometrial cancer may be diagnosed following presentation with abnormal findings on routine cervical screening (Wright 2007) or following evaluation for an incidental thickening of the womb lining found on ultrasound or magnetic resonance imaging (MRI) performed for other reasons (Arora 2012). Endometrial cancer may also be discovered incidentally following a hysterectomy performed for benign womb disease.

Treatment of endometrial cancer is usually surgical and involves the removal of the womb, cervix, both fallopian tubes and 
ovaries. This may, in some women, be followed by chemotherapy, radiotherapy, or both, particularly in those who are deemed as high-risk for recurrence, based on the type and stage of their cancer (Colombo 2016). Hormonal treatments may be offered to young women with early stage disease (FIGO stages I and II) (Appendix 1), who wish to preserve their fertility, and to severely obese women, in whom surgery may be high risk. For those diagnosed with advanced disease (FIGO stages III and IV), there are no effective curative options and palliative chemotherapy is the mainstay of treatment. The use of chemotherapy, however, is not without considerable side effects, many of which impact quality of life $(\mathrm{QoL})$. There is also the possibility of the cancer progressing, leading to poor survival outcomes (Sundar 2017). Women of child-bearing age with endometrial cancer face a dilemma when making treatment choices, as hysterectomy prevents future fertility, and alternative options, such as hormonal manipulations, are not as effective and risk cancer progression (Gallos 2012).

Survival from endometrial cancer depends on the stage at diagnosis, with age-adjusted five-year survival estimates averaging over $90 \%$ in early stage disease and less than $20 \%$ in advanced disease (CRUK 2019). By enabling the early detection of atypical hyperplasia (primary prevention) and early stage endometrial cancer (secondary prevention), an effective screening test will dramatically improve outcomes, as disease can be picked up at the earliest possible opportunity, when treatment is able to effect a cure. Early detection of the clinically aggressive non-endometrioid endometrial cancer will particularly improve outcomes for those diagnosed with this potentially fatal disease (Sundar 2017). There are, however, a number of harms that may result from screening for endometrial cancer that relate mostly to false positive and false negative results. False positive screening test results can lead to extreme anxiety and worry. In addition, women with these test results may be offered invasive diagnostic tests and treatments that are unnecessary, subjecting them to the associated risks of these procedures. False negative screening test results, on the other hand, will reassure women that they do not have endometrial cancer, when in fact they do. Such women may present much later with more advanced disease, leading to a poorer survival outcome. There is also the concern of over diagnosis, where screening detects slow-growing 'harmless' cancers that would, under normal circumstances, pose little or no threat to a woman's health. The potential benefits of screening must therefore be weighed against the risks and harms that may result (Woolf 2012).

A glossary of commonly used terms is summarised in Appendix 2.

\section{Index test(s)}

An ideal endometrial cancer screening test should be easy to perform and interpret, reliable and accurate, with few false positives and false negatives. There are several potential screening tools (Table 1 ) that vary in the level of their supporting evidence in terms of accuracy, acceptability and test-related burden.

\section{Transvaginal ultrasound}

A transvaginal ultrasound scan (TVUSS) is presently the primary imaging test for the initial evaluation of symptomatic women. The diagnostic utility of TVUSS is based on the measurement of the endometrial thickness (ET), a known non-specific marker of endometrial cancer risk (Fleischer 2001; Sundar 2017). Measurement of ET is usually done by scanning the womb in a sagittal (longitudinal) view and reported as a double-layer thickness, measured in an anteroposterior dimension from one basalis layer (deeper layer of the womb lining) to the other with the exclusion of any fluid within the womb (Van den 2012). Measurement of ET using TVUSS is minimally invasive, precise and is useful when the womb lining is uniform. In the presence of localised growths within the womb, a biopsy is usually required (Timmermans 2010). Based on an ovarian cancer screening trial where postmenopausal women underwent between seven and 11 annual screens, there is evidence to suggest that TVUSS based screening causes little discomfort or pain, and is thus likely to be acceptable as a screening tool for endometrial cancer (Jacobs 2011). In some women, however, such as those with an atrophic vagina, vaginismus or a previous sexual assault, the procedure can be traumatic and painful. The use of ET measurement for screening has a number of limitations, the most important of which is its low specificity, as multiple benign conditions including polyps, blood clots or even artefacts can create the appearance of a thickened endometrium (Smith-Bindman 1998). Due to its suboptimal specificity, symptomatic women with thickened endometria are offered further invasive tests in order to establish a diagnosis. The British Gynaecological Cancer Society (BGCS) recommends that every ET measurement on TVUSS of $4 \mathrm{~mm}$ or more should be investigated further. In the absence of any irregularity with and an ET of less than $4 \mathrm{~mm}$, no further investigations are necessary, except in cases of recurrent PMB (Sundar 2017). ET measurement is less useful for the detection of non-endometrioid endometrial cancer, as these are commonly associated with an atrophied endometrium (Gentry-Maharaj 2020). Sometimes, the endometrium may not be visualised due to distortion of the womb cavity, commonly caused by fibroids within the womb. In premenopausal women, the use of TVUSS for endometrial cancer detection is limited by the cyclical fluctuations in ET. Use of hormone replacement therapy (HRT) and tamoxifen can also influence the optimal ET cut-off value (Colombo 2016). Other factors that preclude the utility of ET measurement for endometrial cancer screening include previous uterine surgery, presence of a uterine mass and obesity (ACOG 2018).

\section{Cervical cytology}

There is interest in the potential of the cervical cytology (smear test), established as a screening test for cervical cancer, to also serve as a screening tool for endometrial cancer (Frias-Gomez 2020). Cytology involves looking at individual cells for evidence of a disease (cancer). As far back as 1981, studies have explored the potential of the smear test to detect endometrial cancer in an asymptomatic population (Koss 1981). A feasibility study of 1280 asymptomatic women aged 45 years and above, who were evaluated by several smear tests, detected eight cases of endometrial cancer and 25 cases of atypical hyperplasia (Koss 1981). The conventional smear test has been reported to have a sensitivity of $40 \%$ to $55 \%$ for endometrial cancer detection and $60 \%$ to $84 \%$, if liquid-based preparations are used (Frias-Gomez 2020; Gu 2001; Guidos 2000; Kurokawa 2014; Schorge 2002). A few proof-ofconcept studies have shown that the performance of cytology for endometrial cancer screening may be improved when combined with technologies that can identify specific gene faults (genomics or epi-genomic technologies). In the study by Kinde 2013, endometrial cancer-associated gene faults were detected in all smear samples of women with endometrial cancer. In another study where the Pap test (cervical smear) was used alongside PapSEEK, a new test that can identify gene faults in DNA obtained from body fluids, a 
sensitivity of around $80 \%$ was reported (Wang 2018). The use of Pap smear for gynaecological screening is generally acceptable to women. In England and Wales, however, only seven in 10 women attend cervical screening, with barriers to attendance that include individual barriers (e.g. fear, embarrassment, lack of transport or childcare), cultural barriers (e.g. stigma associated with a disease related to sexual activity), and societal barriers (e.g. lack of access to healthcare providers and resources for screening) (Bennett 2018).

\section{Endometrial cytology}

Endometrial cytology is an endometrial cancer screening strategy in Japan that started in 1987 as a national health project (Fujiwara 2012). This 'selective screening' focuses on women aged 50 years and over, who are postmenopausal, and women with abnormal vaginal bleeding (Sato 1998). Several studies have explored the effectiveness of this approach for endometrial cancer detection (Bistoletti 1988; Byrne 1990; Fujiwara 2012; Fujiwara 2015; LaPolla 1990; Sato 1998; Yoshida 2001). In the study by Fujiwara and colleagues, endometrial cytology had a high sensitivity for detecting advanced stage and non-endometrioid endometrial cancer, but at the risk of potentially misdiagnosing early stage disease (Fujiwara 2012; Fujiwara 2015). In Japan, a higher five-year survival rate has been reported for women diagnosed through the screening pathway, compared to those diagnosed in the outpatient clinics via the usual clinical pathway (Nakagawa-Okamura 2002). Although endometrial cytology has been used in a wide variety of populations, from asymptomatic women to high-risk groups, its accuracy for endometrial cancer detection is still unclear, particularly when used for populationlevel screening (Tajima 1998).

\section{Potential screening tests based on minimally invasive sampling}

There is emerging evidence to suggest that endometrial cancer may be diagnosed from urogenital specimens obtained using minimally invasive sampling methodologies and that these may hold potential as screening tests for endometrial cancer. Uterine lavage, for example, may be an effective sampling method in which to detect genetic faults observed in endometrial cancer. A PTEN mutation was detected in the uterine lavage fluid of an asymptomatic postmenopausal woman with no clinical or pathologic evidence of endometrial cancer, 10 months prior to its clinical detection (Martignetti 2017). In the study by Nair 2016, there were endometrial cancer-associated gene faults in the lavage specimens of all women with cancer and in a significant proportion of women who did not have cancer, suggesting that they may represent signs of pre-cancer in those women (Nair 2016). This study was, however, based on a symptomatic population. Multiple studies have explored the potential of cervicovaginal secretions (Calis 2015; Finan 2012); endocervical swabs (Heng 2016; Lai 2016; Lim 2018); cervical scrapings, vaginal swabs/tampons (BakkumGamez 2015: Fiegl 2004); blood-based markers such as proteins (Diefenbach 2007; Moore 2008; Njoku 2019a; Tarney 2019); and metabolites (Audet-Delage 2018; Ihata 2014; Knific 2018; Njoku 2020a), as well as urine tests for the detection of endometrial cancer in symptomatic women (Njoku 2020b; Shao 2016; Srivastava 2018). It remains unclear whether these approaches are effective for endometrial cancer detection in the general population.

\section{Imaging tests}

Imaging using computed tomography (CT) and MRI scans are other potential screening tests for endometrial cancer. Franconeri and colleagues assessed the utility of ET on sagittal post-contrast $\mathrm{CT}$ and report that an ET of $8 \mathrm{~mm}$ or greater in asymptomatic postmenopausal women had $86 \%$ sensitivity and $91 \%$ specificity for the opportunistic detection of endometrial cancer (Franconeri 2019). The use of CT scans for screening is, however, not without risks, including the risk of an increase in cancers caused by $X$ ray exposure. CT scan is also not sensitive enough to accurately measure ET or detect endometrial cancer. MRI scans, on the other hand, are able to differentiate between benign and malignant causes of post-menopausal bleeding in women, with a sensitivity of up to $96 \%$ (Takeuchi 2009). MRI scans are non-invasive and unlike CT scans, do not involve radiation. Their utility is, however, limited by high equipment and examination costs.

\section{Hysteroscopy}

Hysteroscopy (camera test) is another potential test, and it refers to the endoscopic examination of the womb cavity with a very fine telescope. By allowing for a direct visualization of the womb, hysteroscopy enables targeted biopsy or removal of abnormalities identified during the procedure (Tahir 1999). The increased training of physicians, availability of smaller diameter hysteroscopes and increased emphasis on vaginoscopic outpatient-based procedures have led to the widespread usage of this technology. This diagnostic modality offers the potential of combining investigation with treatment and also avoids the risk of missing a focal pathology, as may occur with the blind Pipelle biopsy. However, hysteroscopy is invasive and often plagued by several operative challenges. In the outpatient setting, severe pain, cervical stenosis and suboptimal visualization are the most frequent reasons for abandonment (Jansen 2000; Tahir 1999). In our scoping search, we did not identify any studies where hysteroscopy was used as a screening test for endometrial cancer in the general population.

\section{Clinical pathway}

There are currently no established programmes for populationlevel screening of endometrial cancer. Neither the American Cancer Society (ACS) nor the BGCS recommend routine screening of asymptomatic women who are at an average risk for endometrial cancer or are at increased risk due to a history of nulliparity, infertility, unopposed oestrogen replacement therapy, tamoxifen therapy or late menopause (Smith 2019; Smith 2005; Sundar 2017). Both societies recommend that such women should be counselled at menopause on the risks and symptoms of endometrial cancer, so that they can in turn alert their general practitioners, should symptoms occur. Although not evidence-based, screening is commonly offered to women at a significantly increased risk of endometrial cancer, such as those who harbour gene faults associated with Lynch syndrome, and those with a strong family history of endometrial cancer. Screening is also offered to those with a suspected autosomal predisposition to colon cancer in the absence of genetic testing (Crosbie 2019; Smith 2019; Sundar 2017).

The clinical pathway for symptomatic women is more defined and evidence-based, although there is currently no international consensus on the order of investigations. When symptomatic with PMB, women in the UK first undergo TVUSS. Depending on their endometrial thickness, a large proportion of women are offered 
further invasive testing, with endometrial biopsy and/or outpatient hysteroscopy, for a definitive diagnosis (Cooper 2014)..

\section{Prior test(s)}

Women may have had a clinical assessment (history and clinical examination) prior to testing with the index test. While those undergoing TVUSS may not have had any other prior test, those undergoing cervical or endometrial cytology may have had TVUSS prior to testing, depending on what point in the screening pathway the index test is being evaluated.

\section{Role of index test(s)}

The index tests to be investigated in this review will be used in clinical practice to triage asymptomatic women for further testing with a more definitive test.

\section{Alternative test(s)}

Given that this review is appraising all potential screening tests for endometrial cancer, there are no alternative tests to report.

\section{Rationale}

Early detection, through screening for pre-malignant and early stage endometrial cancer, is crucial for an improved diseasefree survival (DFS) and overall survival (OS). It would enable conservative management options to be available to women still wishing to preserve their fertility and for morbidly obese women in whom surgery may be potentially hazardous. However, there is insufficient evidence at present to recommend screening in the general population, due to lack of robust and acceptable diagnostic accuracy estimates of the available potential screening tools. Among the most important research priorities identified by patients, the public and healthcare professionals for the UKled James Lind Alliance Detecting Cancer Early Priority Setting Partnership (JLA-PSP), the question of developing screening tests for cancers not currently screened for was ranked within the top 10 (Badrick 2019). Findings from this review could therefore inform future research proposals.

This Cochrane Review will appraise all population-level screening tests for endometrial cancer in order to identify the most accurate test or tests available. Findings from this review will provide policymakers, clinicians and, importantly, women with the muchneeded balanced and robust evidence to guide interpretation of potential endometrial cancer screening test results. It will also inform the decision to implement screening programmes for endometrial cancer at a population level. This review will be carried out with a global perspective as some screening tests have been mainly explored in certain regions of the world. High-risk groups, such as those with Lynch syndrome, will be excluded from this review, as the index tests and test thresholds for this group are different from those of the general population. For example, transvaginal ultrasound screening for endometrial cancer in Lynch syndrome is not useful, because screening is focused on premenopausal women, in whom cyclical fluctuation of endometrial thickness is normal and does not indicate pathology; whereas in postmenopausal women of the general population, transvaginal ultrasound scanning may accurately discriminate benign from malignant disease.

\section{O B JECT IVES}

To assess the diagnostic accuracy of potential screening tests for the detection of atypical hyperplasia (pre-cancer) and endometrial cancer of all stages and grades in asymptomatic (healthy) women in the general population.

\section{Secondary objectives}

- To determine the optimal endometrial thickness cut-off value using transvaginal ultrasound scan for the screening of asymptomatic women for endometrial cancer and atypical hyperplasia.

- To investigate sources of heterogeneity in endometrial cancer screening studies, including:

* characteristics of the studied population including age, menopausal status (pre- and postmenopausal), country of study and risk status (body mass index (BMI) categories, diabetes mellitus, polycystic ovary syndrome (PCOS));

* characteristics of index test such as cytological classification used and sampling device;

* methodological quality (low risk of bias compared to high risk of bias);

* disease factors (endometrioid versus non-endometrioid, low grade versus high grade).

\section{METHODS}

\section{Criteria for considering studies for this review}

\section{Types of studies}

We will include all cross-sectional and comparative diagnostic accuracy studies in which asymptomatic women received one or more of any of the index screening tests, in addition to the reference standard. We will exclude diagnostic case-control studies, as they are known to overestimate performance in diagnostic test accuracy reviews (Deeks 2005). However, there will be no limitation on the number of participants in the included studies. We will include studies published as full article papers, and where studies are available only in an abstract form, we will contact the authors for the full data. Where the authors are unable to provide full data needed for analysis, we will analyse the studies narratively but will exclude them from subsequent meta-analyses (see Appendix 3).

\section{Participants}

We will focus on studies carried out on an asymptomatic (healthy) population of women. There will be no restriction based on age or menopausal status. We will, however, collect data on menopausal status and the proportion of women aged 45 years or over in the studied populations. We will exclude studies focused on high-risk women such as those with Lynch syndrome or a family history of Lynch syndrome or endometrial cancer as well as studies done on a symptomatic population. We will also exclude studies where women have previously had surgery to remove their wombs (hysterectomy).

\section{Index tests}

The index tests include TVUSS, cervical and endometrial cytology and molecular and genetic tests using novel minimally invasive sampling methodologies as described above. For cervical and endometrial cytology, abnormal cells of uncertain significance or 
worse will be used as diagnostic threshold as per the Bethesda system (Nayar 2014). Where a different cytological classification is used, such as the British Society for Clinical Cytology (BSCC) (Denton 2008) or the Munich Cytological classification (Griesser 2013), they will be re-classified using their equivalents in the Bethesda system (Nayar 2014) (see Appendix 4).

\section{Target conditions}

The target condition is endometrial cancer of all grades and stages and will be defined histologically by the invasion of malignant endometrial cells beyond the endometrium. The secondary target condition is atypical endometrial hyperplasia, an endometrioid endometrial cancer precursor lesion, defined by WHO recommendations 2014, as "hyperplasia with evidence of cytological atypia" (Emons 2015). We will assess whether these definitions were applied in each included study. Where a different definition such as the WHO 1994 classification is used, we will state explicitly which criteria were used.

\section{Reference standards}

The reference standard is histological confirmation of endometrial cancer based on either endometrial biopsy, hysterectomy or dilatation and curettage specimens. For studies where participants with a negative index test do not go on to have a tissue diagnosis, we will use follow-up information for at least one year as reference standard. The use of different reference standards, although likely to impact on the validity of study findings, is consistent with current clinical practice. We will, however, perform a sub-group analysis based on the reference standard used.

\section{Search methods for identification of studies}

We have developed a comprehensive search strategy in collaboration with the information specialist of the Gynaecological, Neuro-oncology and Orphan Cancers group (see Appendix 5). We will search the literature using key words from the study titles, abstracts, text words and indexing terms. There will be no search limitation based on language or date of publication. We will have articles written in languages other than English translated by native speakers.

\section{Electronic searches}

We will search the following electronic databases:

- MEDLINE via Ovid (1946 to current date) (Appendix 5);

- Embase via Ovid (1980 to current date);

- BIOSIS Citation Index (1996 to current date);

We will also conduct a PubMed search in order to identify recent trials not indexed by MEDLINE, and Web of Science for relevant conference abstracts.

We will search the following review databases in order to identify relevant systematic reviews based on the primary studies to be included in our review.

- PROSPERO
- ARIF
- HTA
- DARE

Databases of the following trial registers will be searched to identify on-going trials.

- ClinicalTrials.gov at the US National Institutes of Health (NIH)

- World Health Organisation (WHO) International Clinical Trials Registry Platform (ICTRP)

\section{Searching other resources}

We will handsearch reference lists of all relevant publications for additional studies or trials and will also review the grey literature and conference proceedings. We will also check the lists of included studies of relevant systematic reviews identified. Where needed, we will contact the principal investigators of relevant studies, in order to clarify aspects of the methods or results that are unclear, or to ask for unpublished/missing data where indicated.

\section{Data collection and analysis}

\section{Selection of studies}

Four review authors (KN, HOF, EJ and NR) working independently and in duplicate will assess whether the titles and abstracts of the search results are eligible for further reading based on the review's inclusion criteria. We will obtain full-text publications of all potentially relevant references. Following this, studies meeting the inclusion criteria will be included in the review. We will resolve any disagreement between review authors by discussion in a consensus meeting, or, if required, we will consult a third review author (EJC). Where necessary, we will contact study authors to confirm inclusion eligibility, to provide data required for the development of $2 \times 2$ tables or to provide further information needed for risk of bias assessment. We will record all excluded studies in a 'Characteristics of excluded studies' table with reasons for exclusion clearly stated. Studies to be included in meta-analysis must have sufficient data to enable development of a $2 \times 2$ contingency table.

\section{Data extraction and management}

Four review authors (KN, HOF, EJ and NR) will independently and in duplicate extract relevant study characteristics onto a pre-piloted data collection form (Appendix 6). The data to be extracted for each index test include: true positives (TP) (i.e. the number of women with a positive index test and endometrial cancer detected using the reference standard); true negatives (TN) (i.e. the number of women with a negative index test result with no endometrial cancer based on the reference standard (biopsy or follow-up data)); false positives (FP) (i.e. the number of women with a positive index test result but no endometrial cancer detected with the reference standard); and false negatives (FN) (i.e. the number of women with a negative index test result but with endometrial cancer based on the reference standard). Where these data are not clearly stated in the articles, we will reconstruct them based on the frequencies reported in the articles. We will merge the extracted data into a $2 \times 2$ table that contains the TP, FP, FN, TN, enter these data into RevMan 5 (Review Manager 2020) and use them to calculate and metaanalyse the sensitivity and specificity measures. We will design a Microsoft Excel (Microsoft Excel 2018) data extraction form to aid extraction and will pilot-test it before finalising it for use..

\section{Assessment of methodological quality}

We developed a tailored Quality Assessment of Diagnostic Accuracy Studies (QUADAS)-2 tool (Whiting 2011) and we summarise it in 
Table 2. We will use this tool to assess the methodological quality of included studies and we will pilot-test it prior to use (Appendix 7).

Four review authors (KN, EJ, HOF and NR) working independently and in duplicate will assess included studies for methodological quality. We will resolve disagreements by consulting a third review author (EJC). We will assess each study for risk of bias and applicability based on the four domains of QUADAS-2 tool: participant selection, index tests, reference standard, and participant flow. We will present a summary of results of the QUADAS-2 assessments of all included studies and summarise the number of studies judged to have low, high or unclear risk of bias/ concerns regarding applicability for each domain. However, we will not generate a summary quality score, because of the welldocumented problems with this approach (Deeks 2009).

\section{Statistical analysis and data synthesis}

We will present an overview of all included studies in a 'Characteristics of included studies' table that includes study design, country of study, test characteristics and study findings. We will calculate estimates of diagnostic accuracy for each study and express the results as sensitivity and specificity with their $95 \%$ confidence intervals. We will display study-specific estimates as coupled forest plots and plot a receiver operating characteristic (ROC) curve per index test. We will use the hierarchical (mixed) models comprising both the bivariate model and the hierarchical summary ROC (HSROC) model for data synthesis (Harbord 2007; Reitsma 2005). The HSROC analysis would be necessary where we have a diagnostic tool that provides a result on a continuous scale, where the cut-off point varies between studies. Otherwise, we would apply the bivariate model. For bivariate analysis, we would use the R package Ime4 and for HSROC, the MetaDAS package in SAS. We will conduct a meta-analysis focused on the primary outcome measures of sensitivity and specificity where there are sufficient studies (two or more) with similar outcome measures per index test. Where there is a common threshold for a given index test across studies, we will present a summary operating point (using the bivariate model) with confidence and prediction regions on the ROC space and 95\% confidence regions. On the other hand, where there are sufficient number of studies analysing different thresholds, as may be expected in the use of endometrial thickness, we will present a summary ROC curve, using the Rutter and Gatsonis HSROC model (Rutter 2001). Where there is heterogeneity in the couple forest plots and there are fewer than four studies, we will not pool data. Comparative accuracy analysis of similar index tests will be presented as a summary ROC curve (shape and relative position) and/or using summary estimates of sensitivlty and specificity. We will undertake a separate analysis restricted to those studies that make direct comparisons between tests. Withinstudy (direct) comparisons will be annotated to distinguish them from between-study (indirect) comparisons. Where possible, we will aim to identify the optimal endometrial thickness threshold for screening by performing a separate meta-analysis of data at each threshold, or for groups with similar thresholds (Jones 2019). For cytology, a binary threshold (presence/absence) will be used, with disease presence defined by results of 'uncertain significance or severe' using the Bethesda classification system, or conversion to this classification. We will appraise the choice of the models once we have insight into the data from included studies.

Where there are missing data, we will in the first instance contact the study investigators to request the missing data. Where the data are still missing, and if they are deemed to be missing at random, we will only analyse the available data (i.e. we will ignore the missing data). However, where data are not missing at random, we will impute the missing data, with predicted values from regression analyses. We will perform a sensitivity analysis to assess how sensitive our results are to the changes in assumptions made, while the potential impact of 'missingness on the study findings will be highlighted in the discussion section. We will use Review Manager 2020, R 2017, SAS 2020 and Stata 2019 for all analyses.

\section{Investigations of heterogeneity}

Where there are sufficient studies, we will formally assess heterogeneity by meta-regression analyses. Covariates will be tested by their inclusion as cofactors in the bivariate model, or their sequential addition to the HSROC model, in order to assess the degree of heterogeneity in test positivity (threshold), accuracy (position of the curve) and shape of the curve. We will use the likelihood ratio tests to assess the statistical significance of including variables in the models.

We will investigate the following sources of heterogeneity for each index test.

\section{Population and study characteristics}

- Age limits

- Menopausal status

- Ethnicity/country of study

- Risk status e.g. BMI categories, diabetic mellitus and PCOS where feasible

- Study date

\section{Index characteristics}

- Cytological classification system

- Urogenital sampling site (for novel molecular tests: uterine versus cervical versus vaginal)

- Sampling device (Pipelle, Tao brush, Endoflower device, SAP-1 brush, Utero brush etc.)

\section{Disease characteristics}

- Histological subtype/tumour grade

- FIGO stage

Where there is evidence of a substantial amount of heterogeneity, we will report this in the 'Summary of findings' tables.

\section{Sensitivity analyses}

Where there are sufficient number of studies investigating the same index test, we will conduct the following sensitivity analyses to assess the effect on summary estimates of restricting the analyses according to the following criteria.

- Studies where a low risk of bias exists for the index test

- Studies where a low risk of bias exists for the reference standard

- Studies classed as low risk on all four domains of the QUADAS-2 tool (Whiting 2011)

We will also conduct a sensitivity analysis based on age (45 years or over), menopausal status(pre-menopausal versus postmenopausal), publication status of included studies, reference 
standard used, and disease type (atypical hyperplasia versus endometrial cancer).

\section{Assessment of reporting bias}

We will not formally assess for publication bias due to the high possibility of misleading results (Deeks 2005). We will, however, try to minimise the risk of publication bias by using a robust and comprehensive search strategy, covering all possible sources, including searches of the grey literature and registries of published and unpublished studies.

\section{Summary of findings for assessing the certainty of the evidence}

We will develop a 'Summary of findings' table for each index test, in line with the GRADE methods (Appendix 8) (Schünemann 2013; Hsu 2011) and with the aid of the GRADEPro GDT online tool (GRADEproGDT 2020). We will present test accuracy results in natural frequencies indicating true and false positives and negatives. We will appraise the body of research evidence for screening based on an assessment of the overall risk of bias of included studies, level of consistency of study results, precision of estimates, presence of publication bias and level of directness of evidence. For each of the main accuracy measures, we will categorise the overall body of evidence as high-certainty evidence, moderate-certainty evidence, low-certainty evidence or very lowcertainty evidence.

\section{ACKNOWLEDGEMENTS}

We would like to thank Jo Morrison (Co-ordinating Editor), Gail Quinn and Clare Jess (Managing Editors) and Tracey Harrison (Assistant Managing Editor) for their help with the editorial process. Special thanks to Jo Platt (Information Specialist) for designing the search strategy and Helen White (Consumer) for providing a user perspective to the review protocol.

This project was supported by the National Institute for Health Research (NIHR), via Cochrane Infrastructure funding to the Cochrane Gynaecological, Neuro-oncology and Orphan Cancer Group. The views and opinions expressed therein are those of the authors and do not necessarily reflect those of the Systematic Reviews Programme, NIHR, NHS or the Department of Health.

The authors and Cochrane Gynaecological, Neuro-oncology and Orphan Cancers team, are very grateful to the following peer reviewers for their time and comments: Martha Hickey, Chumnan Kietpeerakool, Fani Kokka, Jayne Lawson, Hans Nagar, Simon Pledge and Katharine Tylko-Hill.

Kelechi Njoku is supported by a Cancer Research UK Manchester Cancer Research Centre Clinical Research Fellowship (C147) A25254) and the Wellcome Trust Manchester Translational Informatics Training Scheme. Helena O'Flynn is supported by the National Institute of Health Research Doctoral Research Fellowship (DRF-2018-11-ST2-054). Eleanor Jones is supported by a grant from the JP Moulton Charitable Foundation. Emma Crosbie is supported by NIHR Manchester Biomedical Research Centre (ISBRC-1215-20007). 


\section{REFERE N CES}

\section{Additional references}

\section{ACOG 2018}

ACOG Committee opinion no 734. The role of transvaginal ultrasonography in evaluating the endometrium of women with postmenopausal bleeding. Obstetrics and Gynecology 2018;131(5):e124-e9.

\section{Arora 2012}

Arora V, Quinn MA. Endometrial Cancer. Best Practice \& Research. Clinical Obstetrics \& Gynaecology 2012;26(3):311-24.

\section{Audet-Delage 2018}

Audet-Delage Y, Villeneuve L, Grégoire J, Plante M, Guillemette C. Identification of metabolomic biomarkers for endometrial cancer and its recurrence after surgery in postmenopausal women. Frontiers in Endocrinology 2018;9:87. [PMID: 29593653]

\section{Badrick 2019}

Badrick E, Cresswell K, Ellis P, Crosbie P, Hall PS, O'Flynn H, et al. Top ten research priorities for detecting cancer early. The Lancet Public Health 2019;19:30185-9.

\section{Bakkum-Gamez 2015}

Bakkum-Gamez JN, Wentzensen N, Maurer MJ, Hawthorne KM, Voss JS, Kroneman TN, et al. Detection of endometrial cancer via molecular analysis of DNA collected with vaginal tampons. Gynecologic Oncology 2015;137(1):14-22.

\section{Bennett 2018}

Bennett KF, Waller J, Chorley AJ, Ferrer RA, Haddrell JB, Marlow LA. Barriers to cervical screening and interest in selfsampling among women who actively decline screening. Journal of Medical Screening 2018;25(4):211-7.

\section{Bistoletti 1988}

Bistoletti P, Hjerpe A, Möllerström G, Bistoletti P. Cytological diagnosis of endometrial cancer and preinvasive endometrial lesions: a comparison of the endo-pap sampler with fractional curettage. Acta Obstetricia et Gynecologica Scandinavica 1988;67(4):343-5.

\section{Braun 2016}

Braun MM, Overbeek-Wager EA, Grumbo RJ. Diagnosis and management of endometrial cancer. American Family Physician 2016;93(6):468-74.

\section{Bray 2018}

Bray F, Ferlay J, Soerjomataram I, Siegel RL, Torre LA, Jemal A. Global cancer statistics 2018: GLOBOCAN estimates of incidence and mortality worldwide for 36 cancers in 185 countries. $C A$ Cancer Journal for Clinicians 2018;68(6):394-424

\section{Brinton 2013}

Brinton LA, Felix AS, McMeekin DS, Creasman WT, Sherman ME, Mutch D, et al. Etiologic heterogeneity in endometrial cancer: evidence from a Gynecologic Oncology Group trial. Gynecologic Oncology 2013;129(2):277-84.

\section{Brooks 2019}

Brooks RA, Fleming GF, Lastra RR, Lee NK, Moroney JW, Son $\mathrm{CH}$, et al. Current recommendations and recent progress in endometrial cancer. CA: a Cancer Journal for Clinicians 2019;69(4):258-79.

\section{Byrne 1990}

Byrne AJ. Endocyte endometrial smears in the cytodiagnosis of endometrial carcinoma. Acta Cytologica 1990;34(3):373-81.

\section{Calis 2015}

Calis P, Yuce K, Basaran D, Salman M C. A new endometrial cancer screening test: Cervicovaginal ca 125. International Journal of Gynecological Cancer 2015;1):1094.

\section{Cancer Genome Atlas Research Network 2013}

Cancer Genome Atlas Research Network, Kandoth C, Schultz N, Cherniack AD, Akbani, R, Liu Y, et al. Integrated genomic characterization of endometrial carcinoma. Nature 2013;497(7447):67-73. [DOI: 10]

\section{Cherniack 2017}

Cherniack AD, Shen H, Walter V, Stewart C, Murray B, Bowlby R, et al. Integrated molecular characterization of uterine carcinosarcoma. Cancer Cell 2017;31(3):411-23. [DOI: 10]

\section{Clarke 2018}

Clarke MA, Long BJ, Del Mar Morillo A, Arbyn M, BakkumGamez JN, Wentzensen N. Association of endometrial cancer risk with postmenopausal bleeding in women: A systematic review and meta-analysis. JAMA 2018;178(9):1210-22.

\section{Clarke 2019}

Clarke MA, Devesa SS, Harvey SV, Wentzensen N. Hysterectomycorrected uterine corpus cancer incidence trends and differences in relative survival reveal racial disparities and rising rates of nonendometrioid cancers. Journal of Clinical Oncology 2019;37(22):1895-908.

\section{Colombo 2016}

Colombo N, Creutzberg C, Amant F, Bosse T, Gonzalez-Martin A Ledermann J, et al. ESMO-ESGO-ESTRO consensus conference on endometrial cancer: diagnosis, treatment and follow-up. International Journal of Gynecological Cancer 2016;26(1):2-30.

\section{Cooper 2014}

Cooper NA, Barton PM, Breijer M, Caffrey O, Opmeer BC, Timmermans A, et al. Cost-effectiveness of diagnostic strategies for the management of abnormal uterine bleeding (heavy menstrual bleeding and post-menopausal bleeding): a decision analysis. Health technology assessment (Winchester, England) 2014;18(24):1-201, v-vi. [PMID: 24767431]

\section{Crosbie 2014}

Crosbie E, Morrison J. The emerging epidemic of endometrial cancer: time to take action. Cochrane Database of Systematic Reviews 2014;10(12):1002. 


\section{Crosbie 2019}

Crosbie EJ, Ryan N, Arends MJ, Bosse T, Burn J, Cornes JM, et al. The Manchester International Consensus Group recommendations for the management of gynecological cancers in Lynch syndrome. Genetics in Medicine 2019;21:1-11.

\section{CRUK 2019}

CRUK. Uterine cancer Incidence and survival statistics [Uterine cancer Incidence and survival statistics]. https:// www.cancerresearchuk.org/health-professional/cancerstatistics/statistics-by-cancer-type/uterine-cancer\#; accessed prior to 11 May 2020.

\section{Deeks 2005}

Deeks J, Macaskill P, Irwig L. The performance of tests of publication bias and other sample size effects in systematic reviews of diagnostic test accuracy was assessed. Journal of Clinical Epidemiology 2005;58(9):882-93.

\section{Deeks 2009}

Deeks JJ, Bossuyt PM, Gatsonis C, editor(s). Cochrane Handbook for Systematic Reviews of Diagnostic Test Accuracy Version 1.0.0. The Cochrane Collaboration, 2013. Available from srdta.cochrane.org.

\section{Denton 2008}

Denton KJ, Herbert A, Turnbull LS, Waddell C, Desai MS, Rana DN, et al. The revised BSCC terminology for abnormal cervical cytology. Cytopathology 19;3(1):137-57.

\section{Diefenbach 2007}

Diefenbach CS, Shah Z, lasonos A, Barakat RR, Levine DA, Aghajanian C, et al. Preoperative serum YKL-40 is a marker for detection and prognosis of endometrial cancer. Gynecologic oncology 2007;104(2):435-42. [PMID: 17023034]

\section{El-Sahwi 2012}

El-Sahwi KS, Schwartz PE, Santin AD. Development of targeted therapy in uterine serous carcinoma, a biologically aggressive variant of endometrial cancer. Expert review of anticancer therapy 2012;12(1):41-9. [PMID: 22149431]

\section{Emons 2015}

Emons G, Beckmann MW, Schmidt D, Mallmann P, Group Uterus commission of the Gynecological Oncology Working. New WHO classification of endometrial hyperplasias. Geburtshilfe und Frauenheilkunde 2015;75(02):135-6.

\section{Faber 2017}

Faber MT, Frederiksen K, Jensen A, Aarslev PB, Kjaer SK. Time trends in the incidence of hysterectomy-corrected overall, type 1 and type 2 endometrial cancer in Denmark 1978-2014. Gynecologic Oncology 2017;146(2):359-67.

\section{Fiegl 2004}

Fiegl H, Gattringer C, Widschwendter A, Schneitter A, Ramoni A, Sarlay D, et al. Methylated DNA collected by tampons-a new tool to detect endometrial cancer. Cancer Epidemiology and Prevention Biomarkers 2004;13(5):882-8.

\section{Finan 2012}

Finan M, Pannell L, Billheimer D, Schambeau L, Blandford J, Rocconi R. A novel method of screening for endometrial cancer. Gynecologic Oncology 2012;1):S165.

\section{Fleischer 2001}

Fleischer AC, Wheeler JE, Lindsay I, Hendrix SL, Grabill S, Kravitz B, et al. An assessment of the value of ultrasonographic screening for endometrial disease in postmenopausal women without symptoms. American Journal of Obstetrics and Gynecology 2001;184(2):70-4.

\section{Franconeri 2019}

Franconeri A, Fang J, Brook A, Brook OR. Asymptomatic endometrial thickening of $8 \mathrm{~mm}$ or greater on postcontrast computed tomography in postmenopausal women is a predictor of endometrial cancer. Journal of Computer Assisted Tomography 2019;43(1):136-42.

\section{Frias-Gomez 2020}

Frias-Gomez J, Benavente Y, Ponce J, Brunet J, Ibáñez R, Peremiquel-Trillas $P$, et al. Sensitivity of cervico-vaginal cytology in endometrial carcinoma: A systematic review and meta-analysis. Cancer Cytopathology 2020;Mar 23:Online ahead of print. [PMID: 32202704]

\section{Fujiwara 2012}

Fujiwara H, Suzuki M. Endometrial cytology for endometrial cancer screening. Nihon Rinsho [Japanese Journal of Clinical Medicine] 2012;70 Suppl 4:345-8.

\section{Fujiwara 2015}

Fujiwara H, Takahashi Y, Takano M, Miyamoto M, Nakamura K, Kaneta $Y$, et al. Evaluation of endometrial cytology: cytohistological correlations in 1,441 cancer patients. Oncology 2015;88(2):86-94.

\section{Gallos 2012}

Gallos ID, Yap J, Rajkhowa M, Luesley DM, Coomarasamy A, Gupta JK. Regression, relapse, and live birth rates with fertilitysparing therapy for endometrial cancer and atypical complex endometrial hyperplasia: a systematic review and metaanalysis. American Journal of Obstetrics and Gynecology 2012;207(4):266.

\section{Gentry-Maharaj 2020}

Gentry-Maharaj A, Karpinskyj C. Current and future approaches to screening for endometrial cancer. Best Practice \& Research Clinical Obstetrics \& Gynaecology 2020;19:30182-8.

\section{GRADEproGDT 2020 [Computer program]}

McMaster University (developed by Evidence Prime) GRADEpro GDT. Version accessed prior to 11 January 2020. Hamilton (ON): McMaster University (developed by Evidence Prime), 2020. Available from gradepro.org.

\section{Gredmark 1995}

Gredmark T, Kvint S, Havel G, Mattsson LA. Histopathological findings in women with postmenopausal bleeding. British Journal of Obstetrics and Gynaecology 1995;102(2):133-6. 


\section{Griesser 2013}

Griesser H, Marquardt K, Jordan B, Kühn W, Neis K, Neumann HH, et al. Munich Nomenclature III [Münchner Nomenklatur III]. Frauenarzt 2013;11:2-7.

\section{Gu 2001}

Gu M, Shi W, Barakat RR, Thaler HT, Saigo PE. Pap smears in women with endometrial carcinoma. Acta Cytologica 2001;45(4):555-60.

\section{Guidos 2000}

Guidos BJ, Selvaggi SM. Detection of endometrial adenocarcinoma with the ThinPrep ${ }^{\circledR}$ Pap Test ${ }^{\top \mathrm{M}}$. Diagnostic Cytopathology 2000;23(4):260-5.

\section{Harbord 2007}

Harbord RM, Deeks JJ, Egger M, Whiting P, Sterne JAC. A unification of models for meta-analysis of diagnostic accuracy studies. Biostatistics 2007;8(2):239-51.

\section{Heng 2016}

Heng S, Stephens AN, Jobling TW, Nie G. Measuring PC activity in endocervical swab may provide a simple and non-invasive method to detect endometrial cancer in post-menopausal women. Oncotarget 2016;7(29):46573.

\section{Hsu 2011}

Hsu J, Brożek JL, Terracciano L, Kreis J, Compalati E, Stein AT, et al. Application of GRADE: making evidence-based recommendations about diagnostic tests in clinical practice guidelines. Implementation Science 2011;6(1):62

\section{Ihata 2014}

Ihata Y, Miyagi E, Numazaki R, Muramatsu T, Imaizumi A, Yamamoto $\mathrm{H}$, et al. Amino acid profile index for early detection of endometrial cancer: verification as a novel diagnostic marker. International journal of clinical oncology 2014;19(2):364-72. [PMID: 23700142]

\section{Jacobs 2011}

Jacobs I, Gentry-Maharaj A, Burnell M, Manchanda R, Singh N, Sharma A, et al. Sensitivity of transvaginal ultrasound screening for endometrial cancer in postmenopausal women: a casecontrol study within the UKCTOCS cohort. Lancet Oncology 2011;12(1):38-48.

\section{Jansen 2000}

Jansen FW, Vredevoogd CB, Van UK, Hermans JO, Trimbos JB, Trimbos-Kemper TCM. Complications of hysteroscopy: a prospective, multicenter study. Obstetrics and Gynecology 2000;96(2):266-70

\section{Jones 2019}

Jones HE, Gatsonsis CA, Trikalinos TA, Welton NJ, Ades A. Quantifying how diagnostic test accuracy depends on threshold in a metaanalysis. 2019 Statistics in medicine;38(24):4789-803.

\section{Kinde 2013}

Kinde I, Bettegowda C, Wang Y, Wu J, Agrawal N, Shih leMing, et al. Evaluation of DNA from the Papanicolaou test to detect ovarian and endometrial cancers. Science Translational Medicine 2013;5(167):167ra4.

\section{Knific 2018}

Knific T, Vouk K, Smrkolj Å, Prehn C, Adamski J, RiÅ3/4ner TL. Models including plasma levels of sphingomyelins and phosphatidylcholines as diagnostic and prognostic biomarkers of endometrial cancer. The Journal of steroid biochemistry and molecular biology 2018;178:312-21. [PMID: 29360580]

\section{Koss 1981}

Koss LG, Schreiber K, Oberlander SG, Moukhtar M, Levine HS, Moussouris HF. Screening of asymptomatic women for endometrial cancer. CA: a Cancer Journal for Clinicians 1981;31(5):300-17.

\section{Kurokawa 2014}

Kurokawa T, Sinagawa A, Yoshida Y. Effective endometrial cancer screening method using liquid-based cytology. Gynecologic Oncology 2014;1):128.

\section{Lai 2016}

Lai HC, Rui-Lan H, Po-Hsuan S, Hui-Chen W, Yu-Jun W. Endometrial cancer screening using cervical DNA methylation. International Journal of Gynecological Cancer 2016;26 (Supplement 3):1014.

\section{LaPolla 1990}

LaPolla JP, Nicosia S, McCurdy C, Songster C, Ruffolo E, Roberts WS, et al. Experience with the EndoPap device for the cytologic detection of uterine cancer and its precursors: a comparison of the EndoPap with fractional curettage or hysterectomy. American Journal of Obstetrics and Gynecology 1990;163(3):1055-9.

\section{Lax 2000}

Lax SF, Kendall B, Tashiro H, Slebos RJ, Hedrick L. The frequency of $\mathrm{p} 53$, K-ras mutations, and microsatellite instability differs in uterine endometrioid and serous carcinoma: evidence of distinct molecular genetic pathways. Cancer 2000;88(4):814-24. [PMID: 10679651]

\section{Le 2017}

Le Gallo M, Rudd ML, Urick ME, Hansen NF, Zhang S, Lozy F, et al. Somatic mutation profiles of clear cell endometrial tumors revealed by whole exome and targeted gene sequencing. Cancer 2017;123(17):3261-8. [PMID: 28485815]

\section{Levine 1998}

Levine RL, Cargile CB, Blazes MS, van Rees B, Kurman RJ, Ellenson LH. PTEN mutations and microsatellite instability in complex atypical hyperplasia, a precursor lesion to uterine endometrioid carcinoma. Cancer research 1998;58(15):3254-8. [PMID: 9699651]

Lim 2018

Lim L, Yang YC, Wu CC, Hsu YT, Chang CL. Screening of endometrial cancer using cervical swab. Journal of Obstetrics and Gynaecology Research 2018;44 (8):1514. 


\section{Lortet-Tieulent 2018}

Lortet-Tieulent J, Ferlay J, Bray F, Jemal A. International patterns and trends in endometrial cancer incidence, 1978-2013. Journal of the National Cancer Institute 2018;110(4):354-61.

\section{Martignetti 2017}

Martignetti J, Nair N, Vanegas OC, Rykunov D, Dashkoff M J, Camacho S, et al. Mutation profiling of uterine lavage fluid detects early-stage endometrial cancers and discovers a prevalent landscape of driver mutations in women without cancer. Gynecologic Oncology 2017;145 (Supplement 1):126.

\section{Microsoft Excel 2018 [Computer program]}

Microsoft Excel. Microsoft Corporation, 2018.

\section{Moore 2008}

Moore RG, Brown AK, Miller MC, Badgwell D, Lu Z, Allard WJ, et al. Utility of a novel serum tumor biomarker HE4 in patients with endometrioid adenocarcinoma of the uterus. Gynecologic oncology 2008;110(2):196-201. [PMID: 18495222]

\section{Morice 2016}

Morice P, Leary A, Creutzberg C, Abu-Rustum N, Darai E. Endometrial cancer. Lancet 2016;387(10023):1094-108.

\section{Mutter 2000}

Mutter GL, Lin MC, Fitzgerald JT, Kum JB, Baak JPA, Lees JA, et al. Altered PTEN expression as a diagnostic marker for the earliest endometrial precancers. Journal of the National Cancer Institute 2000;92(11):924-30.

\section{Nair 2016}

Nair N, Camacho-Vanegas O, Rykunov D, Dashkoff M, Camacho SC, Schumacher CA, et al. Genomic analysis of uterine lavage fluid detects early endometrial cancers and reveals a prevalent landscape of driver mutations in women without histopathologic evidence of cancer: A prospective crosssectional study. PLoS Medicine 2016;13(e1002206):12.

\section{Nakagawa-Okamura 2002}

Nakagawa-Okamura C, Sato S, Tsuji I, Kuramoto H, Tsubono Y, Aoki D, et al. Effectiveness of mass screening for endometrial cancer. Acta Cytologica 2002;46(2):277-83.

\section{Nayar 2014}

Nayar R, Wilbur D (Eds). The Bethesda system for reporting cervical cytology. Definitions, criteria, and explanatory notes. Springer International Publishing, 2015.

\section{Njoku 2019}

Njoku K, Abiola J, Russell J, Crosbie EJ. Endometrial cancer prevention in high risk women. Best Practice \& Research. Clinical Obstetrics \& Gynaecology 2019;19:30181-6.

\section{Njoku 2019a}

Njoku K, Chiasserini D, Whetton AD, Crosbie EJ. Proteomic biomarkers for the detection of endometrial cancer. Cancers 2019;11(10):1572.

\section{Njoku 2020a}

Njoku K, Sutton CJ, Whetton AD, Crosbie EJ. Metabolomic Biomarkers for Detection, Prognosis and Identifying Recurrence in Endometrial Cancer. Metabolites 2020;10(8):314.

\section{Njoku 2020b}

Njoku Kelechi, Chiasserini Davide, Jones Eleanor R, et al. Urinary biomarkers and their potential for the non-invasive detection of endometrial cancer. Frontiers in Oncology 03 November 2020

\section{R 2017 [Computer program]}

R Foundation for Statistical Computing R: A language and environment for statistical computing. Version Version3.4.2. Vienna: R Foundation for Statistical Computing, 2017.

\section{Reitsma 2005}

Reitsma JB, Glas AS, Rutjes AWS, Scholten RJ, Bossuyt PM, Zwinderman AH. Bivariate analysis of sensitivity and specificity produces informative summary measures in diagnostic reviews. Journal of Clinical Epidemiology 2005;58(10):982-90.

\section{Review Manager 2020 [Computer program]}

Copenhagen: Nordic Cochrane Centre, 2014.The Cochrane Collaboration Review Manager 5 (RevMan 5) [Computer program]. Version 5.4. Copenhagen: Nordic Cochrane Centre, 2014.The Cochrane Collaboration, 2020.

\section{Rutter 2001}

Rutter MC, Gatsonis CA. A hierarchical regression approach to meta-analysis of diagnostic test accuracy evaluations. Statistics in Medicine 2001;20:2865-84.

\section{Ryan 2019}

Ryan NAJ, Glaire MA, Blake D, Cabrera-Dandy M, Evans DG, Crosbie EJ. The proportion of endometrial cancers associated with Lynch syndrome: a systematic review of the literature and meta-analysis. Genetics in medicine : official journal of the American College of Medical Genetics 2019;21(10):2167-80. [PMID: 31086306]

\section{SAS 2020 [Computer program]}

SAS Institute Inc SAS. Version X.x. Cary, NC, USA: SAS Institute Inc, 2020.

\section{Sato 1998}

Sato S, Matsunaga G, Konno R, Yajima A. Mass screening for cancer of the endometrium in Miyagi Prefecture, Japan. Acta Cytologica 1998;42(2):295-8.

\section{Schorge 2002}

Schorge JO, Hossein SM, Hynan L, Ashfaq R. ThinPrep detection of cervical and endometrial adenocarcinoma: a retrospective cohort study. Cancer Cytopathology: Interdisciplinary International Journal of the American Cancer Society 2002;96(6):338-43.

\section{Schünemann 2013}

Schünemann H, Brożek J, Guyatt G, Oxman A, . GRADE handbook for grading quality of evidence and strength of recommendations. Updated October 2013.. The GRADE Working 
Group, 2013. Available from guidelinedevelopment.org/ handbook.

\section{Setiawan 2013}

Setiawan VW, Yang HP, Pike MC, McCann SE, Yu H, Xiang Y-B, et al. Type I and II endometrial cancers: have they different risk factors? Journal of Clinical Oncology 2013;31(20):2607.

\section{Shao 2016}

Shao X, Wang K, Liu X, Gu C, Zhang P, Xie J, et al. Screening and verifying endometrial carcinoma diagnostic biomarkers based on a urine metabolomic profiling study using UPLC-Q-TOF/MS. Clinica Chimica Acta 2016;463:200-6.

\section{Sherman 1995}

Sherman ME, Bur ME, Kurman RJ. p53 in endometrial cancer and its putative precursors: evidence for diverse pathways of tumorigenesis. Human Pathology 1995;26(11):1268-74.

\section{Smith 2005}

Smith RA, Cokkinides V, Eyre HJ. American Cancer Society guidelines for the early detection of cancer, 2005. CA: a Cancer Journal for Clinicians 2005;55(1):31-44.

\section{Smith 2019}

Smith RA, Andrews KS, Brooks D, Fedewa SA, Manassaram BD, Saslow D, et al. Cancer screening in the United States, 2019: A review of current American Cancer Society guidelines and current issues in cancer screening. CA: a Cancer Journal for Clinicians 2019;69(3):184-210.

\section{Smith-Bindman 1998}

Smith-Bindman R, Kerlikowske K, Feldstein VA, Subak L, Scheidler J, Segal M, et al. Endovaginal ultrasound to exclude endometrial cancer and other endometrial abnormalities. Jama 1998;280(17):1510-7.

\section{Srivastava 2018}

Srivastava A, Moxley Ka, Ruskin R, Dhanasekaran DN, Zhao YD, Ramesh R. A non-invasive liquid biopsy screening of urinederived exosomes for miRNAs as biomarkers in endometrial cancer patients. AAPS Journal 2018;20(5):82.

\section{Stata 2019 [Computer program]}

Stata. Version 16. College Station, TX USA: StataCorp, 2019.

\section{Stelloo 2015}

Stelloo E, Bosse T, Nout RA, MacKay HJ, Church DN, Nijman HW, et al. Refining prognosis and identifying targetable pathways for high-risk endometrial cancer; a TransPORTEC initiative. Modern Pathology 2015;28(6):836.

\section{Suarez 2017}

Suarez AA, Felix AS, Cohn DE. Bokhman redux: Endometrial cancer "types" in the 21st century. Gynecologic Oncology 2017;144(2):243-9.

\section{Sundar 2017}

Sundar S, Balega J, Crosbie E, Drake A, Edmondson R, Fotopoulou C, et al. BGCS uterine cancer guidelines: recommendations for practice. European Journal of Obstetrics, Gynecology, and Reproductive Biology 2017;213:71-97.

\section{Tahir 1999}

Tahir MM, Bigrigg MA, Browning JJ, Brookes T, Smith PA. A randomised controlled trial comparing transvaginal ultrasound, outpatient hysteroscopy and endometrial biopsy with inpatient hysteroscopy and curettage. BJOG: An International Journal of Obstetrics \& Gynaecology 1999;106(12):1259-64.

\section{Tajima 1998}

Tajima M, Inamura M, Nakamura M, Sudo Y, Yamagishi K. The accuracy of endometrial cytology in the diagnosis of endometrial adenocarcinoma. Cytopathology: official journal of the British Society for Clinical Cytology 1998;9(6):369-80.

\section{Takeuchi 2009}

Takeuchi M, Matsuzaki K, Nishitani H. Diffusion-weighted magnetic resonance imaging of endometrial cancer: differentiation from benign endometrial lesions and preoperative assessment of myometrial invasion. Acta Radiologica 2009;50(8):947-53.

\section{Talhouk 2017}

Talhouk A, McConechy MK, Leung S, Yang W, Lum A, Senz J, et al. Confirmation of ProMisE: A simple, genomics-based clinical classifier for endometrial cancer. Cancer 2017;123(5):802-13.

\section{Tarney 2019}

Tarney CM, Wang G, Bateman NW, Conrads KA, Zhou M, Hood BL, et al. Biomarker panel for early detection of endometrial cancer in the Prostate, Lung, Colorectal, and Ovarian cancer screening trial. American journal of obstetrics and gynecology 2019;221(5):472.e1-472.e10. [PMID: 31279844]

\section{Temkin 2016}

Temkin SM, Minasian L, Noone AM. The end of the hysterectomy epidemic and endometrial cancer incidence: what are the unintended consequences of declining hysterectomy rates? Frontiers in Oncology 2016;6:89.

\section{Timmermans 2010}

Timmermans A, Opmeer BC, Khan KS, Bachmann LM, Epstein E, Clark TJ, et al. Endometrial thickness measurement for detecting endometrial cancer in women with postmenopausal bleeding: a systematic review and meta-analysis. Obstetrics and Gynecology 2010;116(1):160-7.

\section{Urick 2019}

Urick ME, Bell DW. Clinical actionability of molecular targets in endometrial cancer. Nature Reviews Cancer 2019;19(9):510-21.

\section{Van den 2012}

Van den BT. Ultrasound in the diagnosis of endometrial and intracavitary pathology: an update. Australasian Journal of Ultrasound in Medicine 2012;15(1):7-12.

\section{Wang 2018}

Wang Y, Li L, Douville C, Cohen JD, Yen TT, Kinde I, et al. Evaluation of liquid from the Papanicolaou test and other liquid 
biopsies for the detection of endometrial and ovarian cancers. Science Translational Medicine 2018;10(433):eaap8793.

\section{Whiting 2011}

Whiting PF, Rutjes AWS, Westwood ME, Mallett S, Deeks JJ, Reitsma JB, et al. QUADAS-2: a revised tool for the quality assessment of diagnostic accuracy studies. Annals of Internal Medicine 2011;155(8):529-36.

\section{Woolf 2012}

Woolf SH, Harris R. The harms of screening: new attention to an old concern. Jama 2012;307(6):565-6.

\section{Wright 2007}

Wright Jr TC, Massad LS, Dunton CJ, Spitzer M, Wilkinson EJ, Solomon D. 2006 consensus guidelines for the management of women with abnormal cervical cancer screening tests. American Journal of Obstetrics and Gynecology 2007;197(4):346-55.

\section{Yoshida 2001}

Yoshida Y, Sato S, Okamura C, Nishino Y, Yajima A. Evaluating the accuracy of uterine cancer screening with the regional cancer registration system. Acta Cytologica 2001;45(2):157-62.

\section{ADDITIONAL TABLES}

Table 1. Index tests for endometrial cancer screening in the general population

\begin{tabular}{|c|c|c|c|}
\hline Tests & Characteristics & Use in current clinical pathway & Other information \\
\hline $\begin{array}{l}\text { Transvaginal } \\
\text { ultrasound } \\
\text { scan (TVUSS) }\end{array}$ & $\begin{array}{l}\text { Insertion of a spe- } \\
\text { cially designed ultra- } \\
\text { sound probe into the } \\
\text { vagina and subse- } \\
\text { quent measurement } \\
\text { of the endometrial } \\
\text { thickness (ET). }\end{array}$ & $\begin{array}{l}\text { Currently used as the initial diagnostic } \\
\text { test in symptomatic women. } \\
\text { It is used to triage women for definitive } \\
\text { testing based on the ET. } \\
\text { In the UK, women with an ET } \geq 4 \mathrm{~mm} \text { are } \\
\text { referred for further invasive testing. } \\
\text { Potential to serve a similar role in the } \\
\text { screening of the general population. }\end{array}$ & $\begin{array}{l}\text { Advantages } \\
\text { Minimally invasive } \\
\text { Safe, causes little discomfort or pain } \\
\text { Useful when the womb lining is uniform } \\
\text { Real time diagnostic test } \\
\text { Disadvantages } \\
\text { Non-definitive } \\
\text { A thick endometrium may not be endometrial } \\
\text { cancer } \\
\text { Sometimes, the endometrium cannot be visu- } \\
\text { alised due to cavity distortion or a stretched } \\
\text { uterine position } \\
\text { Operator-dependent }\end{array}$ \\
\hline
\end{tabular}

\section{Cervical cytol- Involves taking sam- ogy \\ ples from the cervix \\ Historically used as a screening test for cervical cancer.}

(smear test) with the aid of a brush or scraping device for cytological analysis.
The finding of atypical (abnormal) endometrial cells usually warrants further investigation for endometrial cancer.

Has potential to serve as a screening test for endometrial cancer.

\section{Advantages}

Widely acceptable to women

Simple and minimally invasive

Inexpensive

\section{Disadvantages}

Intimate procedure

Discomfort from speculum examination

Contact bleeding

Does not involve direct sampling of the endometrium, hence may miss endometrial cancer

Dependent on experience of the cytologist which may vary widely. 
Table 1. Index tests for endometrial cancer screening in the general population (Continued)

$\begin{array}{ll}\text { Endometrial } & \text { Cytology of cells } \\ \text { cytology } & \text { obtained from the } \\ & \text { womb lining using a } \\ \text { brush, lavage or suc- } & \text { tion technique. Sam- } \\ \text { pling devices may in- } & \text { clude EndPap, En- } \\ \text { docyte, Endoflower } & \text { device, Tao brush, } \\ \text { Utero brush, SAP-1 } & \text { brush etc. }\end{array}$

Currently used in Japan to screen postmenopausal women aged 50 years and over, and women presenting with abnormal vaginal bleeding.

Not in clinical use in most Western countries.

\section{Advantages}

Involves a direct sampling of the endometrium

Potential for targeted sampling when used alongside hysteroscopy.

Potential for histological examination of obtained samples.

\section{Disadvantages}

Relatively invasive

Pain and discomfort.

May miss focal pathologies if done blindly.

Risk of infection, bleeding and perforation.

Less useful in women with cervical stenosis (due to high-risk of insertion failure)

\begin{tabular}{|c|c|c|}
\hline Imaging & $\begin{array}{l}\text { Use of imaging tests } \\
\text { such as computed } \\
\text { tomography (CT) } \\
\text { or magnetic reso- } \\
\text { nance imaging (MRI) } \\
\text { scans to take pic- } \\
\text { tures of the inside of } \\
\text { the womb to detect } \\
\text { endometrial cancer. }\end{array}$ & $\begin{array}{l}\text { Not routinely used in the current en- } \\
\text { dometrial cancer diagnostic pathway. } \\
\text { MRI or CT scan of the abdomen and } \\
\text { pelvis is often used to plan treatment. } \\
\text { It is recommended that women with en- } \\
\text { dometrial cancer that has potentially } \\
\text { spread outside the womb should have } \\
\text { CT of the chest, abdomen and pelvis } \\
\text { to plan for surgery or prevent upfront } \\
\text { surgery if evidence of spread is found. }\end{array}$ \\
\hline
\end{tabular}

\section{Advantages}

$\mathrm{CT}$ and MRI are painless and non-invasive.

MRI scans are safe and do not expose women to $X$-ray radiation.

\section{Disadvantages}

CT scans can induce cancer from $X$-ray exposure.

MRI scans are expensive

Women with metal fragments can not undergo an MRI scan.

\section{Advantages}

Allows for direct visualisation of the womb lining.

Enables targeted biopsy of suspicious lesions

Facilitates removal of suspicious lesions(therapeutic)

\section{Disadvantages}

Invasive

Operative challenges are common

May be abandoned due to severe pain, cervical stenosis or sub-optimal visualisation.

\section{Advantages}

Non and minimally invasive
Blood, urine and use of vaginal tampons/endocervical swabs may be used as screening tests based on their potential to enable the detection of endome-

\section{A variety of index} and minimally invasive sampling
Currently used in the diagnostic patha high-risk of endometrial cancer, espelar endometrium. Hysteroscopy along side biopsy is also used in cases of recurrent PMB 
Table 1. Index tests for endometrial cancer screening in the general population (Continued)

methodologies and include blood based markers, urine test$\mathrm{s}$, use of vaginal tampons/endocervical swabs amongst others. trial cancer related genetic faults, proteins and metabolites.
Likely to be acceptable to women and physicians.

Urine and vaginal tampons can be self-collected

\section{Disadvantages}

Blood-based tests may be limited by the low amount of cancer related signals in the blood in early stage cancer.

Vaginal tampons are unappealing to elderly women.

Biomarkers may not be excreted in urine.

CT: computed tomography; ET: endometrial thickness; MRI: magnetic resonance imaging; PMB: postmenopausal bleeding; TVUSS: transvaginal ultrasound scan

Table 2. Tailored QUADAS-2 tool for assessment of methodological quality of included studies

Item Response

\title{
Participant selection: Risk of bias
}

1) Was a consecutive or random sample of women enrolled?

2) Was a case-control design avoided?

Yes if the study participants were randomly or consecutively selected.

No if non-consecutive or convenience sampling was used.

Unclear if the provided information is insufficient to enable an assessment of the sampling technique used.

Yes if all participants were recruited from the same population. Those diagnosed with endometrial cancer should not have been recruited from a separate population from those without endometrial cancer.

No if women with endometrial cancer were recruited from a separate population from those without endometrial cancer.

Unclear if the available information is insufficient to make a judgement on whether a case-control design was avoided.

3) Did the study avoid inappropriate exclusions? Exclusion of symptomatic women and those at a high risk of EC such as women with LS are appropriate exclusions.
Yes if inappropriate exclusions were avoided.

No if a group of women were inappropriately excluded that may affect the study tests accuracy.

Unclear if the provided information is unclear as to who was excluded and whether this was appropriate.

\section{Could the selection of participants have introduced bias?}

\author{
If answers to all of questions 1) and 2) and 3) Risk is low \\ was Yes
}
If answers to any of questions 1) and 2) and Risk is high
3) was No


Table 2. Tailored QUADAS-2 tool for assessment of methodological quality of included studies (Continued)

If answers to any of questions 1) and 2) and

3) was Unclear
Risk is unclear

\section{Participant selection: Concerns regarding applicability}

Is there concern that the included participants do not match the review question?

Low concerns if the study participants are representative of the full spectrum of women likely to be eligible for a population-level EC screening programme.

High concerns if study participants are not representative of the spectrum of women who will be eligible for a population-level EC screening programme.

This may include studies done exclusively in: obese women, pre-menopausal women, narrow age distribution, narrow group of ethnicity that will impact on the applicability of the study findings to other group of asymptomatic women.

Unclear concerns if the provided information is insufficient to enable an assessment of the applicability of the study.

\section{Index test: Risk of bias (to be completed per test evaluated)}

1) Were the index test results interpreted without knowledge of the results of the reference standard?
Yes if the index test was performed and interpreted prior to the completion of the reference standard or if there was a clear statement that the interpretation of the index test result was done without knowledge of the reference standard.

No if the index test was either conducted or interpreted following completion of the reference standard.

Unclear if the provided information is unclear to enable a judgement of the blinding of the index test interpretation to the reference standard results.

Yes if the threshold for a positive test discrimination was pre-specified.

No if the threshold for a positive test discrimination was not pre-specified or if the threshold was defined based on the study data, e.g ROC-optimised.

Unclear if the provided information is insufficient to make a judgement on whether the threshold was pre-specified.

\section{Could the conduct or interpretation of the index test have introduced bias?}

\begin{tabular}{ll}
\hline If answers to all of questions 1) and 2), & Risk is low \\
\hline If answers to any of questions 1) and 2) & Risk is high \\
\hline If answers to any of questions 1) and 2) & Risk is unclear \\
\hline $\begin{array}{l}\text { Index test: Concerns regarding applicabil- } \\
\text { ity }\end{array}$ & \\
\hline $\begin{array}{l}\text { 1) Was the interpretation of index test re- } \\
\text { sults such as ET or cytology performed by } \\
\text { someone with expertise? }\end{array}$ & Yes if interpretation of index test was performed by an expert \\
& No if interpretation of index test was not performed by an expert \\
\hline
\end{tabular}




\section{Table 2. Tailored QUADAS-2 tool for assessment of methodological quality of included studies (Continued)}

2) Were thresholds or diagnostic criteria reported in enough detail to allow replication?
Yes if the criteria used for the diagnosis of endometrial cancer based on the index test were reported in sufficient detail to enable replication or can be assumed based on international standards such as ET.

No if the criteria used for the diagnosis of endometrial cancer were not reported in sufficient detail to enable replication.

Unclear if the available information on the diagnostic criteria is insufficient to allow for replication.

\section{Are there concerns that the index test, its conduct, or interpretation may not be ap- plicable in clinical practice?}$$
\text { If the answer to question 1) and 2) was Yes }
$$

If the answer to question 1) and 2) was No

If the answer to question 1) and 2) was Unclear

\section{Reference standard: Risk of bias}

1) Is the reference standard likely to correctly classify the target condition

\section{Low concern}

High concerns

\section{Concern is unclear}

Yes if the final diagnosis was based on a histological assessment of endometrial tissue specimens (obtained by biopsy, dilation and curettage or following hysterectomy) or follow up information of at least a year for those with a negative index test.

No if the final diagnosis was not based upon histological assessment of endometrial tissue specimens or follow up information of at least a year.

Unclear if there was insufficient information to make a judgement.

2) Were the reference standard results interpreted without knowledge of the results of the index test?
Yes if the reference standard examiner was described as blinded to the index test result

No if the reference standard examiner was described as having knowledge of the index test result

Unclear if blinded reference standard interpretation was not clearly reported or where blinding cannot be assumed based on provided information.

\section{Could the reference standard, its conduct, or its interpretation have introduced bias?}

\begin{tabular}{|c|c|}
\hline If answers to questions 1) and 2) was Yes & Risk is low \\
\hline If the answer to question 1) and 2) was No & Risk is high \\
\hline $\begin{array}{l}\text { If the answer to question 1) and 2) was Un- } \\
\text { clear }\end{array}$ & Risk is unclear \\
\hline \multicolumn{2}{|l|}{$\begin{array}{l}\text { Reference test: Concerns regarding ap- } \\
\text { plicability }\end{array}$} \\
\hline $\begin{array}{l}\text { 1) Does the study use the same definition of } \\
\text { disease positive as that prescribed in the re- } \\
\text { view question? }\end{array}$ & $\begin{array}{l}\text { Low concerns if same definition of disease-positive was used, i.e histological diagno- } \\
\text { sis endometrial cancer or atypical hyperplasia. }\end{array}$ \\
\hline
\end{tabular}


Table 2. Tailored QUADAS-2 tool for assessment of methodological quality of included studies (Continued)

High concerns if an alternative definition of disease-positive was used.

Unclear if the definition of disease-positive was not clearly reported

\section{Flow and timing: Risk of bias}

1) Was there an appropriate interval between index test and reference standard? Was the interval between the reference standard and the index test short enough to ensure that the target condition did not change between the two tests?

2) Did all participants receive the same reference standard?
Yes if the index test and reference standard were performed at a suitable interval.

No if the index test and reference standard were not performed at a suitable interval.

Unclear if the study does not report the interval between the index test and reference standard.

Yes if all participants underwent histological sampling or follow up where clinically indicated as per the protocol.

No if participants did not have histological sampling performed or were not followed up for at least a year where index test was negative as per protocol.

Unclear if not clearly reported.

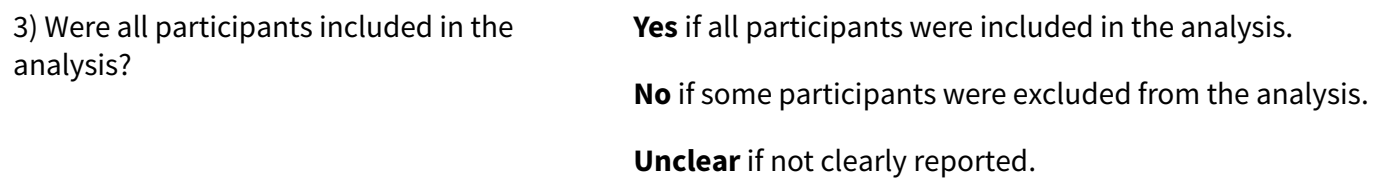

Yes if all participants were included in the analysis.

No if some participants were excluded from the analysis.

Unclear if not clearly reported.

If answers to all of questions 1) and 2) and 3) Risk is low was Yes
If answers to any of questions 1) and 2) and
Risk is high
3) was No
If answers to any of questions 1 ) and 2) and
3) was Unclear

\section{Risk is unclear}

EC: endometrial cancer; ET: endometrial thickness;LS: Lynch syndrome; ROC: receiver operating characteristic

\section{AP PEN DICES}

\section{Appendix 1. FIGO Staging of endometrial cancer}

\begin{tabular}{ll}
\hline Tumour Stage & Description \\
\hline I & Tumour confined to the uterus (womb) \\
\hline I A & $<50 \%$ invasion of the myometrium \\
\hline I B & $\geq 50 \%$ invasion of the myometrium \\
\hline II & Tumour invades the cervical stroma buy does not extend beyond the uterus. \\
\hline III & Local or regional spread of tumour \\
\hline III A & Serosal or adnexal invasion \\
\hline \hline
\end{tabular}




\begin{tabular}{ll} 
III B & Vaginal or parametrial involvement \\
\hline III C & Pelvic or paraaortic lymph node metastasis \\
\hline III C1 & Pelvic lymph node involvement \\
\hline III C2 & Paraaortic lymph node involvement (with or without pelvic nodes) \\
\hline IV & Extension to the pelvic wall, one-third of the vagina, hydronephrosis or non-functioning kidney. \\
\hline IV A & Invasion of bladder or bowel mucosa. \\
\hline IV B & Distant metastasis including abdominal or inguinal lymph node involvement.
\end{tabular}

\section{Appendix 2. Glossary of terms}

\begin{tabular}{|c|c|}
\hline Term & Definition \\
\hline Advanced stage womb cancers & $\begin{array}{l}\text { Cancers that have grown beyond the womb to nearly structures and distant organs. These are usu- } \\
\text { ally FIGO stages III and IV. }\end{array}$ \\
\hline Anteroposterior & Front to back \\
\hline Atrophic endometrium & Abnormal thinning of the lining of the womb \\
\hline Atypical hyperplasia & Pre-cancer \\
\hline Autosomal & Traits that can be passed down in families relating to chromosomes other than the $\mathrm{X}$ chromosome \\
\hline Benign & Not harmful (non-cancer) \\
\hline Cervical cytology & Pap smear test \\
\hline Chemotherapy & Medications that can kill cancer cells or stop them from multiplying \\
\hline Cytology & Examining cells for evidence of cancer \\
\hline Early stage womb cancers & Small cancers that are localised to the womb. These are usually FIGO stages I and II. \\
\hline Endometrial biopsy & Removal of a small piece of tissue from the lining of the womb \\
\hline Endometrial polyp & Growths attached to the lining of the womb \\
\hline Endometrial thickness & Amount of thickening of the inner lining of the womb \\
\hline Endometrium & Inner lining of the womb \\
\hline Gene & A hereditary unit transferred from parents to their off-springs \\
\hline Grade & How abnormal and how fast-growing cells appear \\
\hline Heterogeneity & Diversity \\
\hline
\end{tabular}


(Continued)

Histology

Microscopic study of tissue specimens for evidence of disease

Human Development Index

Hyperplasia

\begin{tabular}{|c|c|}
\hline Histology & Microscopic study of tissue specimens for evidence of disease \\
\hline Human Development Index & A measure of life expectancy, education and income that is used to rank countries. \\
\hline Hyperplasia & Too many cells \\
\hline Hypertension & Persistent elevation in blood pressure \\
\hline Hysterectomy & Surgical removal of the womb and the cervix \\
\hline Hysteroscopy & A camera test used to visualize and take samples from the womb \\
\hline Incidence & Total number of new cases of a disease \\
\hline Index tests & The screening tests or procedures to be evaluated in this review \\
\hline Lynch syndrome & $\begin{array}{l}\text { Inherited condition due to specific gene faults (MMR mutations) with increased predisposition to } \\
\text { endometrial and colon cancers. }\end{array}$ \\
\hline Late-menopause & Menopause occuring after the age of 55 years. \\
\hline Molecular genetic tests & Tests that aim to identify underlying gene changes \\
\hline Mutations & Gene faults \\
\hline Non-specific marker & A test that is not diagnostic but may along with other tests aid diagnosis \\
\hline Nulliparity & Never given birth before \\
\hline Obesity & Excess body weight/fat based on a body mass index of more than $30 \mathrm{~kg} / \mathrm{m}^{2}$ \\
\hline Polycystic ovarian syndrome & $\begin{array}{l}\text { A medical condition in which women have a hormonal imbalance and metabolism problems lead- } \\
\text { ing to infertility and obesity }\end{array}$ \\
\hline Polymerase epsilon & A gene that codes for an enzyme that plays a role in DNA repair and has been linked to cancer \\
\hline Post-menopausal bleeding & $\begin{array}{l}\text { Bleeding occurring at least } 12 \text { months after the end of menstruation in women not taking a hor- } \\
\text { mone treatment. }\end{array}$ \\
\hline Prevalence & Total number of people with a disease (both old and new cases) \\
\hline Prognosis & Predicted outcome \\
\hline PTEN & $\begin{array}{l}\text { A gene (phosphatase and tensine homologue) that gives instructions for making a specific enzyme } \\
\text { which regulates the rate at which cells grow and divide. }\end{array}$ \\
\hline Radiotherapy & High energy X-rays used to treat cancer \\
\hline Screening & Detecting a disease in healthy people before they develop symptoms \\
\hline Sensitivity & The ability of a test to correctly identify those that have a disease \\
\hline Specificity & The ability of a test to correctly identify those who do not have a disease \\
\hline Sporadic & Occurring randomly in the population \\
\hline
\end{tabular}

\begin{tabular}{|c|c|}
\hline Histology & Microscopic study of tissue specimens for evidence of disease \\
\hline Human Development Index & A measure of life expectancy, education and income that is used to rank countries. \\
\hline Hyperplasia & Too many cells \\
\hline Hypertension & Persistent elevation in blood pressure \\
\hline Hysterectomy & Surgical removal of the womb and the cervix \\
\hline Hysteroscopy & A camera test used to visualize and take samples from the womb \\
\hline Incidence & Total number of new cases of a disease \\
\hline Index tests & The screening tests or procedures to be evaluated in this review \\
\hline Lynch syndrome & $\begin{array}{l}\text { Inherited condition due to specific gene faults (MMR mutations) with increased predisposition to } \\
\text { endometrial and colon cancers. }\end{array}$ \\
\hline Late-menopause & Menopause occuring after the age of 55 years. \\
\hline Molecular genetic tests & Tests that aim to identify underlying gene changes \\
\hline Mutations & Gene faults \\
\hline Non-specific marker & A test that is not diagnostic but may along with other tests aid diagnosis \\
\hline Nulliparity & Never given birth before \\
\hline Obesity & Excess body weight/fat based on a body mass index of more than $30 \mathrm{~kg} / \mathrm{m}^{2}$ \\
\hline Polycystic ovarian syndrome & $\begin{array}{l}\text { A medical condition in which women have a hormonal imbalance and metabolism problems lead- } \\
\text { ing to infertility and obesity }\end{array}$ \\
\hline Polymerase epsilon & A gene that codes for an enzyme that plays a role in DNA repair and has been linked to cancer \\
\hline Post-menopausal bleeding & $\begin{array}{l}\text { Bleeding occurring at least } 12 \text { months after the end of menstruation in women not taking a hor- } \\
\text { mone treatment. }\end{array}$ \\
\hline Prevalence & Total number of people with a disease (both old and new cases) \\
\hline Prognosis & Predicted outcome \\
\hline PTEN & $\begin{array}{l}\text { A gene (phosphatase and tensine homologue) that gives instructions for making a specific enzyme } \\
\text { which regulates the rate at which cells grow and divide. }\end{array}$ \\
\hline Radiotherapy & High energy X-rays used to treat cancer \\
\hline Screening & Detecting a disease in healthy people before they develop symptoms \\
\hline Sensitivity & The ability of a test to correctly identify those that have a disease \\
\hline Specificity & The ability of a test to correctly identify those who do not have a disease \\
\hline Sporadic & Occurring randomly in the population \\
\hline
\end{tabular}

Lynch syndrome

Late-menopause

Molecular genetic tests

\begin{tabular}{|c|c|}
\hline Histology & Microscopic study of tissue specimens for evidence of disease \\
\hline Human Development Index & A measure of life expectancy, education and income that is used to rank countries. \\
\hline Hyperplasia & Too many cells \\
\hline Hypertension & Persistent elevation in blood pressure \\
\hline Hysterectomy & Surgical removal of the womb and the cervix \\
\hline Hysteroscopy & A camera test used to visualize and take samples from the womb \\
\hline Incidence & Total number of new cases of a disease \\
\hline Index tests & The screening tests or procedures to be evaluated in this review \\
\hline Lynch syndrome & $\begin{array}{l}\text { Inherited condition due to specific gene faults (MMR mutations) with increased predisposition to } \\
\text { endometrial and colon cancers. }\end{array}$ \\
\hline Late-menopause & Menopause occuring after the age of 55 years. \\
\hline Molecular genetic tests & Tests that aim to identify underlying gene changes \\
\hline Mutations & Gene faults \\
\hline Non-specific marker & A test that is not diagnostic but may along with other tests aid diagnosis \\
\hline Nulliparity & Never given birth before \\
\hline Obesity & Excess body weight/fat based on a body mass index of more than $30 \mathrm{~kg} / \mathrm{m}^{2}$ \\
\hline Polycystic ovarian syndrome & $\begin{array}{l}\text { A medical condition in which women have a hormonal imbalance and metabolism problems lead- } \\
\text { ing to infertility and obesity }\end{array}$ \\
\hline Polymerase epsilon & A gene that codes for an enzyme that plays a role in DNA repair and has been linked to cancer \\
\hline Post-menopausal bleeding & $\begin{array}{l}\text { Bleeding occurring at least } 12 \text { months after the end of menstruation in women not taking a hor- } \\
\text { mone treatment. }\end{array}$ \\
\hline Prevalence & Total number of people with a disease (both old and new cases) \\
\hline Prognosis & Predicted outcome \\
\hline PTEN & $\begin{array}{l}\text { A gene (phosphatase and tensine homologue) that gives instructions for making a specific enzyme } \\
\text { which regulates the rate at which cells grow and divide. }\end{array}$ \\
\hline Radiotherapy & High energy X-rays used to treat cancer \\
\hline Screening & Detecting a disease in healthy people before they develop symptoms \\
\hline Sensitivity & The ability of a test to correctly identify those that have a disease \\
\hline Specificity & The ability of a test to correctly identify those who do not have a disease \\
\hline Sporadic & Occurring randomly in the population \\
\hline
\end{tabular}

Polycystic ovarian syndrome

Polymerase epsilon

\begin{tabular}{|c|c|}
\hline Histology & Microscopic study of tissue specimens for evidence of disease \\
\hline Human Development Index & A measure of life expectancy, education and income that is used to rank countries. \\
\hline Hyperplasia & Too many cells \\
\hline Hypertension & Persistent elevation in blood pressure \\
\hline Hysterectomy & Surgical removal of the womb and the cervix \\
\hline Hysteroscopy & A camera test used to visualize and take samples from the womb \\
\hline Incidence & Total number of new cases of a disease \\
\hline Index tests & The screening tests or procedures to be evaluated in this review \\
\hline Lynch syndrome & $\begin{array}{l}\text { Inherited condition due to specific gene faults (MMR mutations) with increased predisposition to } \\
\text { endometrial and colon cancers. }\end{array}$ \\
\hline Late-menopause & Menopause occuring after the age of 55 years. \\
\hline Molecular genetic tests & Tests that aim to identify underlying gene changes \\
\hline Mutations & Gene faults \\
\hline Non-specific marker & A test that is not diagnostic but may along with other tests aid diagnosis \\
\hline Nulliparity & Never given birth before \\
\hline Obesity & Excess body weight/fat based on a body mass index of more than $30 \mathrm{~kg} / \mathrm{m}^{2}$ \\
\hline Polycystic ovarian syndrome & $\begin{array}{l}\text { A medical condition in which women have a hormonal imbalance and metabolism problems lead- } \\
\text { ing to infertility and obesity }\end{array}$ \\
\hline Polymerase epsilon & A gene that codes for an enzyme that plays a role in DNA repair and has been linked to cancer \\
\hline Post-menopausal bleeding & $\begin{array}{l}\text { Bleeding occurring at least } 12 \text { months after the end of menstruation in women not taking a hor- } \\
\text { mone treatment. }\end{array}$ \\
\hline Prevalence & Total number of people with a disease (both old and new cases) \\
\hline Prognosis & Predicted outcome \\
\hline PTEN & $\begin{array}{l}\text { A gene (phosphatase and tensine homologue) that gives instructions for making a specific enzyme } \\
\text { which regulates the rate at which cells grow and divide. }\end{array}$ \\
\hline Radiotherapy & High energy X-rays used to treat cancer \\
\hline Screening & Detecting a disease in healthy people before they develop symptoms \\
\hline Sensitivity & The ability of a test to correctly identify those that have a disease \\
\hline Specificity & The ability of a test to correctly identify those who do not have a disease \\
\hline Sporadic & Occurring randomly in the population \\
\hline
\end{tabular}

\begin{tabular}{|c|c|}
\hline Histology & Microscopic study of tissue specimens for evidence of disease \\
\hline Human Development Index & A measure of life expectancy, education and income that is used to rank countries. \\
\hline Hyperplasia & Too many cells \\
\hline Hypertension & Persistent elevation in blood pressure \\
\hline Hysterectomy & Surgical removal of the womb and the cervix \\
\hline Hysteroscopy & A camera test used to visualize and take samples from the womb \\
\hline Incidence & Total number of new cases of a disease \\
\hline Index tests & The screening tests or procedures to be evaluated in this review \\
\hline Lynch syndrome & $\begin{array}{l}\text { Inherited condition due to specific gene faults (MMR mutations) with increased predisposition to } \\
\text { endometrial and colon cancers. }\end{array}$ \\
\hline Late-menopause & Menopause occuring after the age of 55 years. \\
\hline Molecular genetic tests & Tests that aim to identify underlying gene changes \\
\hline Mutations & Gene faults \\
\hline Non-specific marker & A test that is not diagnostic but may along with other tests aid diagnosis \\
\hline Nulliparity & Never given birth before \\
\hline Obesity & Excess body weight/fat based on a body mass index of more than $30 \mathrm{~kg} / \mathrm{m}^{2}$ \\
\hline Polycystic ovarian syndrome & $\begin{array}{l}\text { A medical condition in which women have a hormonal imbalance and metabolism problems lead- } \\
\text { ing to infertility and obesity }\end{array}$ \\
\hline Polymerase epsilon & A gene that codes for an enzyme that plays a role in DNA repair and has been linked to cancer \\
\hline Post-menopausal bleeding & $\begin{array}{l}\text { Bleeding occurring at least } 12 \text { months after the end of menstruation in women not taking a hor- } \\
\text { mone treatment. }\end{array}$ \\
\hline Prevalence & Total number of people with a disease (both old and new cases) \\
\hline Prognosis & Predicted outcome \\
\hline PTEN & $\begin{array}{l}\text { A gene (phosphatase and tensine homologue) that gives instructions for making a specific enzyme } \\
\text { which regulates the rate at which cells grow and divide. }\end{array}$ \\
\hline Radiotherapy & High energy X-rays used to treat cancer \\
\hline Screening & Detecting a disease in healthy people before they develop symptoms \\
\hline Sensitivity & The ability of a test to correctly identify those that have a disease \\
\hline Specificity & The ability of a test to correctly identify those who do not have a disease \\
\hline Sporadic & Occurring randomly in the population \\
\hline
\end{tabular}

A medical condition in which women have a hormonal imbalance and metabolism problems leading to infertility and obesity

A gene that codes for an enzyme that plays a role in DNA repair and has been linked to cancer

Bleeding occurring at least 12 months after the end of menstruation in women not taking a horBleeding occurring
mone treatment.

Inherited condition due to specific gene faults (MMR mutations) with increased predisposition to endometrial and colon cancers.

Menopause occuring after the age of 55 years.

Tests that aim to identify underlying gene changes

Gene faults

A test that is not diagnostic but may along with other tests aid diagnosis

Never given birth before

Excess body weight $/$ fat based on a body mass index of more than $30 \mathrm{~kg} / \mathrm{m}^{2}$

Surgical removal of the womb and the cervix

A camera test used to visualize and take samples from the womb

Total number of new cases of a disease

The screening tests or procedures to be evaluated in this review 
(Continued)

Stage How far the disease has spread

\begin{tabular}{ll}
\hline Tamoxifen & A medication used to treat and prevent breast cancer but which also increases risk of EC \\
\hline Transvaginal ultrasound & A type of scan which uses a vaginal probe to examine the female reproductive organs \\
\hline Tumour & Abnormal growth that may or may not be cancer \\
\hline Uterine lavage & Washing the womb cavity with water \\
\hline Uterus & Womb \\
\hline
\end{tabular}

\section{Appendix 3. Review eligiblity criteria}

\begin{tabular}{lll}
\hline Study characteris- & Inclusion criteria & Exclusion criteria \\
tics &
\end{tabular}

Population Asymptomatic(healthy) women in the general population. No restriction based on age or menopausal status.

Symptomatic women such as those with postmenopausal bleeding.

Women at very high risk of endometrial cancer such as those with Lynch syndrome (not representative of the general population).

Women who have had surgery to remove their wombs (hysterectomy).

No limitations provided test was carried out on the appropriate population

All potential screening tests including TVUSS, cervical cytology, endometrial cytology, molecular/genetic tests based on minimally invasive sampling techniques including uterine lavage, cervico-vaginal secretions and vaginal tampons.

Reference standard Histology of endometrial tissue based on biopsy, hysterectomy specimens or dilation and curettage specimens.

Follow up information for at least 1 year for participants with a negative test who do not go on to have endometrial biopsy

\begin{tabular}{lll}
\hline Outcomes & Any of: & $\begin{array}{l}\text { Studies in which diagnostic performance of } \\
\text { the index tests were not investigated. }\end{array}$ \\
& $\begin{array}{l}\text { Sensitivity and specificity } \\
\text { Positive predictive value and negative predictive value } \\
\text { Positive likelihood ratio and negative likelihood ratio }\end{array}$ \\
\hline Study designs & $\begin{array}{l}\text { All cross sectional and comparative diagnostic test accuracy } \\
\text { studies }\end{array}$ & Case control study designs \\
\hline
\end{tabular}

Studies not meeting the inclusion criteria of a reference standard.

TVUSS: transvaginal ultrasound scan

\section{Appendix 4. Cytology reclassification scheme}




\begin{tabular}{llc}
\hline Bethesda classification & British Society for Clinical Cytology (BSCC) & Munich III \\
\hline ASCUS & Borderline & Pap IIw \\
\hline LSIL & Mild dyskaryosis & Pap IIID \\
& Glandular cells & \\
\hline
\end{tabular}

ASCUS: Atypical squamous cells of undetermined significance. LSIL: Low-grade sqaumous intra-epithelial lesion

\section{Appendix 5. MEDLINE search strategy}

\section{BB10: Screening tests for endometrial cancer in the general population}

1. exp Endometrial Neoplasms/

2. (endom ${ }^{\star}$ adj5 (cancer ${ }^{\star}$ or neoplas ${ }^{\star}$ or carcinom ${ }^{\star}$ or adenocarcinom ${ }^{\star}$ or malignan ${ }^{\star}$ or tumor ${ }^{\star}$ or tumour ${ }^{\star}$ or hyperplasia* or lesion ${ }^{\star}$ or abnormal ${ }^{\star}$ or disease $\left.\left.{ }^{\star}\right)\right) . t i, a b, k w$.

3. ((uter ${ }^{\star}$ and lining) adj5 (cancer ${ }^{\star}$ or neoplas ${ }^{\star}$ or carcinom ${ }^{\star}$ or adenocarcinom ${ }^{\star}$ or malignan ${ }^{\star}$ or tumor ${ }^{\star}$ or tumour or lesion $^{\star}$ or abnormal ${ }^{\star}$ or disease $\left.\left.{ }^{\star}\right)\right) . t i, a b, k w$.

4. ((womb or corpus uter $\left.{ }^{\star}\right)$ adj5 (cancer ${ }^{\star}$ or neoplas ${ }^{\star}$ or carcinom* or adenocarcinom ${ }^{\star}$ or malignan* or tumor ${ }^{\star}$ or tumour ${ }^{\star}$ or lesion* or abnormal $^{*}$ or disease*)).ti,ab,kw.

5. Endometrial Hyperplasia/

6. 1 or 2 or 3 or 4 or 5

7. ((cervi ${ }^{\star}$ or uter $^{\star}$ or endometrial or endometrium or endocervical or endo-cervical or cervico-vaginal or vaginal* or urine or intrauterine)

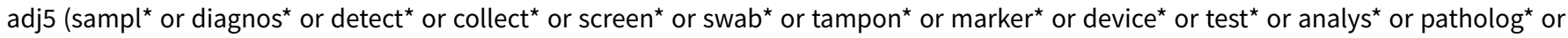
smear $^{\star}$ or lavage ${ }^{\star}$ or scrap* or suction or vacuum ${ }^{\star}$ or tool or tools or aspirat* or biops ${ }^{\star}$ or brush* or technique* or tecnic or tecnics or liquid*)).ti,ab,kw.

8. cyto*.ti,ab,kw.

9. 7 and 8

10. (cervi ${ }^{\star}$ or uter $^{\star}$ or endometrial or endometrium or endocervical or endo-cervical or cervico-vaginal or vaginal ${ }^{\star}$ ).ti,ab,kw.

11. cytodiagnosis/

12. 10 and 11

13. Tomography, X-Ray Computed/

14. (Computed tomography scan ${ }^{\star}$ or CT scan ${ }^{\star}$ ).ti,ab,kw.

15. Magnetic Resonance Imaging/

16. (magnetic resonance imag* or MRI).ti,ab,kw.

17. $\left(\right.$ abdom $^{\star}$ or pelvi $\left.{ }^{\star}\right) . t i, a b, k w$.

18. 13 or 14 or 15 or 16

19. 17 and 18

20. hysteroscopy/

21. hysteroscop*.ti,ab,kw.

22. (transvaginal ultraso* or trans-vaginal ultraso* or TVS or TVUSS or transvaginal scan* or trans-vaginal scan* or sonograph*).ti,ab,kw.

23. (pap* adj3 (test or tests or testing or smear)).ti,ab,kw.

24. Hematologic Tests/

25. 10 and 24

26. (CA-125 or HE4).ti,ab,kw.

27. (blood $^{\star}$ or serum $^{\star}$ or plasma or protein ${ }^{\star}$ or peptide* or proteomic $^{\star}$ or metabolite ${ }^{\star}$ or metabolomic $\left.{ }^{\star}\right)$.ti,ab,kw.

28. 7 and 27

29. ultrasonography/

30.19 or 20 or 21 or 22 or 23 or 25 or 26 or 28 or 29

31. exp "sensitivity and specificity"/

32. "reproducibility of results"/

33. diagnos*.ti.

34. di.fs.

35. sensitivit*.ab.

36. specificit*.ab.

37. (ROC or "receiver operat*").ab.

38. Area under curve/

39. ("Area under curve" or AUC).ab. 
40. sROC.ab.

41. accura*.ti,ab.

42. (likelihood adj3 (ratio* or function $\left.{ }^{\star}\right)$ ).ab.

43. ((true or false) adj3 (positive* or negative $\left.{ }^{\star}\right)$ ).ab.

44. ((positive* or negative* or false or true) adj3 rate*).ti,ab.

45.31 or 32 or 33 or 34 or 35 or 36 or 37 or 38 or 39 or 40 or 41 or 42 or 43 or 44

46. Asymptomatic Diseases/

47. (subclinical $^{\star}$ or sub-clinical $\left.{ }^{\star}\right) . t i, a b, k w$.

48. asymptomatic.ti,ab,kw.

49. 46 or 47 or 48

50.6 or 9 or 12

51.45 and 50 and 30

52.49 and 50 and 30

53.51 or 52

\section{Key:}

$\mathrm{mp}=$ title, abstract, original title, name of substance word, subject heading word, keyword heading word, protocol supplementary concept word, rare disease supplementary concept word, unique identifier

\section{Appendix 6. Data extraction form for study characteristics and diagnostic accuracy estimates}

\section{General Information}

Reviewer: (Initials)

Unique review ID: (All studies to be reviewed will be given a unique ID from 1 to $n$ )

Date of extraction: $(d d / m m / y y y y)$

Study ID: (surname of first author and year of publication of first study report e.g. Jones 2020)

Publication status: (e.g. published full report, conference abstract, letter)

Country of study:

Title of article:

Study author contact details:

Report ID of other reports of this study including errata or retractions

Notes:

\section{Study eligibility}

\begin{tabular}{|c|c|c|c|c|}
\hline $\begin{array}{l}\text { Study Character- } \\
\text { istics }\end{array}$ & Eligibility criteria & Eligibility criteria met? & $\begin{array}{l}\text { If eli- } \\
\text { gibili- } \\
\text { ty not } \\
\text { met, } \\
\text { in- } \\
\text { clude } \\
\text { de- }\end{array}$ & $\begin{array}{l}\text { Loca- } \\
\text { tion in } \\
\text { text or } \\
\text { source } \\
\text { (page } \\
\text { num- } \\
\text { ber) }\end{array}$ \\
\hline
\end{tabular}




\begin{tabular}{llll} 
& & $\begin{array}{c}\text { tails } \\
\text { why }\end{array}$ \\
\hline Yes & No & $\begin{array}{l}\text { Un- } \\
\text { clear }\end{array}$ & $\begin{array}{l}\text { De- } \\
\text { tails }\end{array}$
\end{tabular}

\begin{tabular}{ll}
\hline Type of study & Prospective cross-sectional study \\
\cline { 2 - 2 } & Prospective comparative study \\
\hline Participants & Asymptomatic (healthy) population of women \\
& Are not at very high risk of EC (LS or family history of LS/EC) \\
\hline Index test & TVUSS \\
& Cervical smear test \\
\hline Reference stan- & Histological diagnosis or follow up for at least one year \\
\hline dard & Endometrial cancer and/or atypical hyperplasia \\
\hline Target condition & Diagnostic accuracy reports( sensitivity, specificity etc) \\
\hline Study outcomes & \\
\hline Include OR Exclude \\
\hline Reason for exclusion:
\end{tabular}

\section{ONLY PROCEED IF STUDY HAS BEEN INCLUDED FOR REVIEW}

\section{Characteristics of included studies}

Methodology

\begin{tabular}{ll}
\hline Study aim & \\
\hline Study setting & $\begin{array}{l}\text { (Clinical or research setting, hospital } \\
\text { or community-based) }\end{array}$
\end{tabular}

\section{Start date}

End date

Duration of follow-up (from recruitment to last follow-up)

\section{Funding}


(Continued)

Possible conflicts of interests

\section{Study participants}

Description

Location in text (page number, figure/table/other)

Population description (from which study participants were drawn)

Study specific inclusion criteria

Study specific exclusion criteria

\begin{tabular}{ll}
\hline Informed consent $\quad$ Yes, No, Not reported &
\end{tabular}

\section{Method of recruitment}

Total number of women consented at start of study

Number analysed at the end

Sample attrition or drop-outs

Age distribution

Race/ethnicity

Menopausal status

Obesity distribution

Use of hormonal treatment

Use of tamoxifen

Other relevant sociodemographic information

\section{Description of index test}

Description as stated in report/paper
Location in text or source (page \& figure/table/other)

Name of index test

Was there a diagnostic threshold?

Yes, No, Unclear

If Yes, was this pre-specified?

Yes, No, Unclear

Screening tests for endometrial cancer in the general population (Protocol)

Copyright $\odot 2021$ The Cochrane Collaboration. Published by John Wiley \& Sons, Ltd. 
(Continued)

Description of index test (include sufficient detail for replication)

If cytology, what reporting system was used?

Timing (e.g. when was test performed in relation to reference standard)

Site of index test (e.g. anatomical area)

Test providers (e.g. profession, training, calibration etc. if relevant)

Assessors of test (e.g profession, training, blinded to reference test results)

Number who received index test

Completion of test (e.g. failure rate and reasons for failure)

Inadequacy rate

Adverse effects reported

Additional notes:

\section{Description of reference standard}

Description as stated in report/paper
Location in text or source (page \& figure/table/other)

\section{Name of reference standard}

Number who received reference standard

Description (include sufficient detail for replication)

Histology reporting system used

Timing (e.g. when was test performed in relation to index test)

Providers (e.g. profession, training etc. if relevant)

Assessors of test (e.g. profession, training, blinded to index test results)

Completion of test (e.g. failure rate and reasons for failure)

Inadequacy rate

Other reference standards used for participants

Number who received 'other' reference standard

Length of follow up of participants 


\section{Target condition}

Description as stated in report/paper
Location in text or source (page \& figure/table/other)

Endometrial cancer only

Atypical hyperplasia only

Both endometrial cancer and $\mathrm{AH}$

Detailed information on grade and stage of cancer detected

Other information

\section{Data and analysis.}

What power was achieved based on eventual sample size?

How was missing data handled?

What comparisons were made

\section{Results}

(Name of index test and standard)

\section{Test positive}

\section{Test negative}

\section{Total}

Number of true positives

Number of true negatives 
(Continued)

Number of false positives

Number of false negatives

Sensitivity $(95 \% \mathrm{Cl})$

Specificity $(95 \% \mathrm{Cl})$

$\operatorname{AUC}(95 \% \mathrm{Cl})$

Any other results reported (e.g. PPV, NPV, positive likelihood ratio, negative like-

lihood ratio, disease prevalence etc.)

No. of missing data

Reasons missing

Unit of analysis (by individuals, cluster/groups or samples)

Statistical methods used and appropriateness of these

Additional notes:

Other information

Description as stated in Location in text or source (page \& figreport/paper

ure/table/other)

Key conclusions of study authors

Correspondence details for further study information

Notes:

AH: Atypical hyperplasia; AUC: Area under the curve; CI: confidence interval; EC: endometrial cancer; LS: Lynch syndrome; NPV: negative predictive value; PPV: positive predictive value; TVUSS: transvaginal ultrasound scan

\section{Appendix 7. Data extraction form for methodological quality assessment}

Data extraction form for methodological quality

$\begin{array}{ll}\text { Item } & \text { Authors judgement } \\ & \text { Description } \\ & \text { (using tailored } \\ \text { QUADAS-2) }\end{array}$


(Continued)

\section{Participant selection: Risk of bias}

1) Were the study participants' representative of women likely to be eligible for a population level endometrial cancer screening programme?

2) Was a consecutive or random sample of patients enrolled?

3) Was a case-control design avoided?

4) Did the study avoid inappropriate exclusions? Exclusion of symptomatic women and those at a high risk of EC such as women with LS are appropriate exclusions.

\section{Participant selection: Concerns regarding applicability}

Is there concern that the included participants do not match the review question?

\section{Index test: Risk of bias (to be completed per test evaluated)}

1) Were the index test results interpreted without knowledge of the results of the reference standard?

2) If an index test threshold was used, such as ET cut-off value for TVS, was this prespecified?

\section{Index test: Concerns regarding applicability}

1) Was the interpretation of index test results such as ET or cytology performed by someone with expertise?

2) Were thresholds or diagnostic criteria reported in enough detail to allow replication?

\section{Are there concerns that the index test, its conduct, or interpretation differ from the review question or may not be applicable in clinical practice?}

\section{Reference standard - Risk of bias}

1) Is the reference standard likely to correctly classify the target condition

2) Were the reference standard results interpreted without knowledge of the results of the index test?

\section{Could the reference standard, its conduct, or its interpretation have introduced bias?}

\section{Reference test: Concerns regarding applicability}

1) Does the study use the same definition of disease positive as that prescribed in the review question?

\section{Flow and timing: Risk of bias}

1) Was there an appropriate interval between index test and reference standard?

Was the interval between the reference standard and the index test short enough to ensure that the target condition did not change between the two tests?

2) Did all participants receive the same reference standard? 
(Continued)

3) Were all participants included in the analysis?

EC: endometrial cancer; ET: endometrial thickness; LS: Lynch syndrome; QUADAS-2: Quality Assessment of Diagnostic Accuracy Studies, version 2; TVS: transvaginal sonography

\section{Appendix 8. Summary of findings template}




\begin{tabular}{|c|c|c|c|c|c|c|c|c|c|}
\hline Index tests & $\begin{array}{l}\text { Study } \\
\text { popula- } \\
\text { tion }\end{array}$ & $\begin{array}{l}\text { Target } \\
\text { condition }\end{array}$ & $\begin{array}{l}\text { Reference } \\
\text { standard }\end{array}$ & $\begin{array}{l}\text { Types of } \\
\text { studies } \\
\text { included }\end{array}$ & $\begin{array}{l}\text { Number } \\
\text { of par- } \\
\text { ticipants } \\
\text { (studies) }\end{array}$ & $\begin{array}{l}\text { Test } \\
\text { threshold }\end{array}$ & $\begin{array}{l}\text { Summary } \\
\text { accuracy } \\
(95 \% \mathrm{Cl})\end{array}$ & $\begin{array}{l}\text { Certain- } \\
\text { ty of evi- } \\
\text { dence }\end{array}$ & $\begin{array}{l}\text { Implica- } \\
\text { tions for } \\
\text { practice }\end{array}$ \\
\hline TVUSS & & & & & & & & & \\
\hline Cervical cytology & & & & & & & & & \\
\hline Endometrial cytology & & & & & & & & & \\
\hline $\begin{array}{l}\text { Hysteroscopy } \\
\text { (camera test) }\end{array}$ & & & & & & & & & \\
\hline Imaging: CT Scan & & & & & & & & & \\
\hline Imaging: MRI scan & & & & & & & & & \\
\hline A specific blood-based test & & & & & & & & & \\
\hline A specific urine-based test & & & & & & & & & \\
\hline Vaginal tampon + genetic testing & & & & & & & & & \\
\hline
\end{tabular}




\section{HISTORY}

Protocol first published: Issue 1, 2021

\section{CONTRIBUTIONS OFAUTHORS}

All authors contributed to the study design. Emma Crosbie is the principal investigator and study guarantor. Kelechi Njoku prepared the first draft of the protocol. Helena O'Flynn, Eleanor Jones, Richard Macey, Helen White and Emma Crosbie provided critical comment, edited the protocol draft, and approved its final version. Richard Macey provided expert methodological input. Data acquisition will be undertaken by Kelechi Njoku, Eleanor Jones Helena O'Flynn and Neal Ramchander. Data analysis and interpretation will be undertaken by Kelechi Njoku, Helena O'Flynn, Eleanor Jones, Neal Ramchander, Richard Macey and Emma Crosbie. Helen White is a consumer co-author and will check that the review is relevant to consumers. Drafting of final review manuscript will be performed by Kelechi Njoku and Emma Crosbie and will be reviewed by all authors. The review update will be undertaken by Kelechi Njoku and Emma Crosbie.

\section{DECLARATIONS OF INTEREST}

Kelechi Njoku: None known Helena O'Flynn: None known

Eleanor Jones: None known Neal Ramchander: None known Helen White: None known Richard Macey: None known Emma Crosbie: None known 